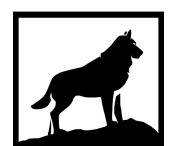

Michigan Technological

1 в 8 5 University
Michigan Technological University Digital Commons @ Michigan Tech

\title{
A COMBUSTION MODEL FOR MULTI-COMPONENT FUELS BASED ON RELATIVE REACTIVITY AND MOLECULAR STRUCTURE
}

Arash Jamali

Michigan Technological University, ajamali@mtu.edu

Copyright 2021 Arash Jamali

Recommended Citation

Jamali, Arash, "A COMBUSTION MODEL FOR MULTI-COMPONENT FUELS BASED ON RELATIVE REACTIVITY AND MOLECULAR STRUCTURE", Open Access Dissertation, Michigan Technological University, 2021.

https://doi.org/10.37099/mtu.dc.etdr/1183

Follow this and additional works at: https://digitalcommons.mtu.edu/etdr

Part of the Heat Transfer, Combustion Commons 


\title{
A COMBUSTION MODEL FOR MULTI-COMPONENT FUELS BASED ON RELATIVE REACTIVITY AND MOLECULAR STRUCTURE
}

\author{
By
}

Arash Jamali

\begin{abstract}
A DISSERTATION
Submitted in partial fulfillment of the requirements for the degree of DOCTOR OF PHILOSOPHY

In Mechanical Engineering-Engineering Mechanics

MICHIGAN TECHNOLOGICAL UNIVERSITY

2021
\end{abstract}

(C) 2021 Arash Jamali 
This dissertation has been approved in partial fulfillment of the requirements for the Degree of DOCTOR OF PHILOSOPHY in Mechanical Engineering-Engineering Mechanics.

Department of Mechanical Engineering-Engineering Mechanics

Dissertation Advisor: Youngchul Ra

Committee Member: $\quad$ Pradeep K. Agrawal

Committee Member: Jeffrey D. Naber

Committee Member: Song-Lin a Yang

Department Chair: William W. Predebon 
Table of Contents

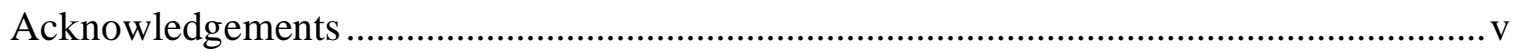

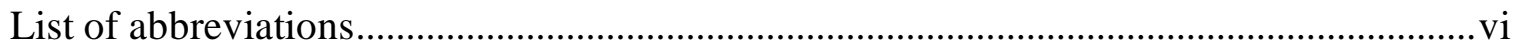

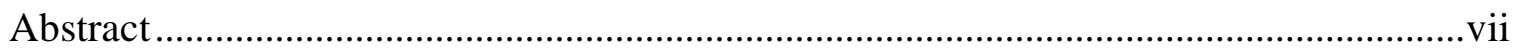

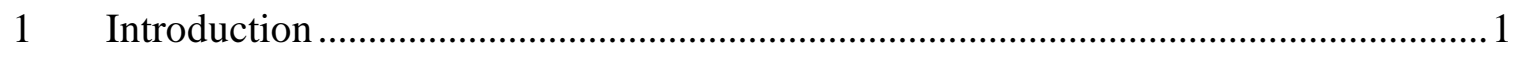

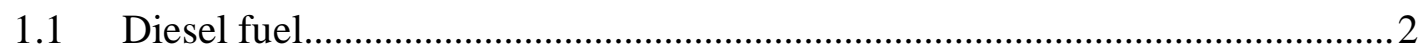

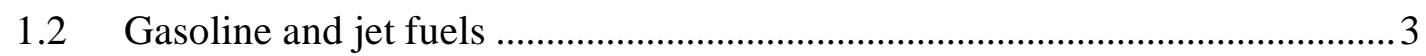

1.3 Combustion models of multi-component fuels .............................................. 3

2 Physical surrogate determination method ........................................................... 6

2.1 Physical surrogate representation examples...................................................... 6

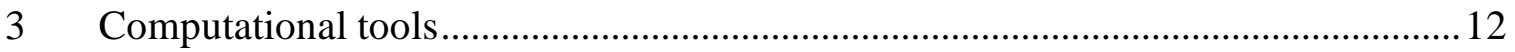

$4 \quad$ Model formulation (Chemical kinetics representation) ......................................... 15

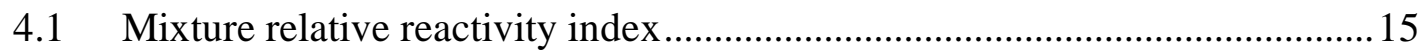

4.2 On-the-fly reactivity adjustment (ReAd) model ........................................... 16

4.3 Reactivity-based re-distribution of fuel components.................................... 17

4.3.1 Prediction of the reaction rate of local mixture.................................19

4.4 Base-CS component for n-alkanes........................................................... 19

4.4.1 Selection of control reactions of $n$-heptane mechanism ...................22

4.4.2 Effect of equivalence ratio on reactivity adjustment ........................24

$5 \quad$ Extension of the model using more base-CS components ......................................27

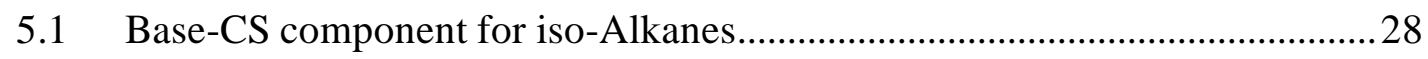

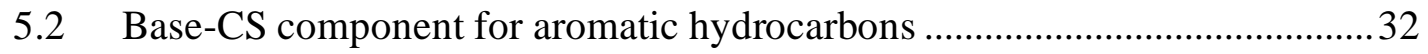

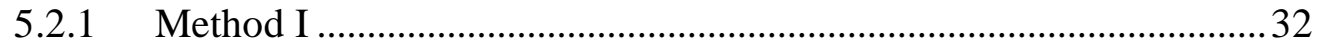

5.2.2 Method II .............................................................................. 34

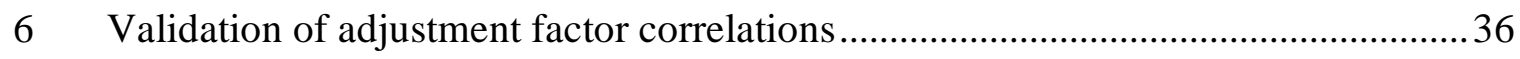

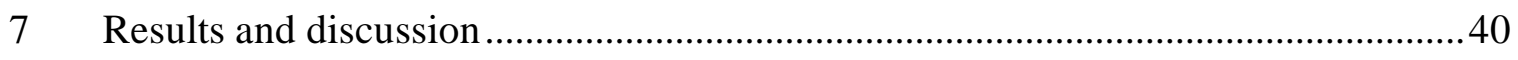

7.1 Ignition of homogeneous mixtures in a constant volume reactor ..................40

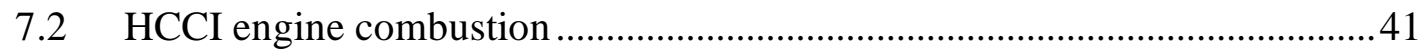

7.3 RCCI engine combustion simulation .............................................................. 46 


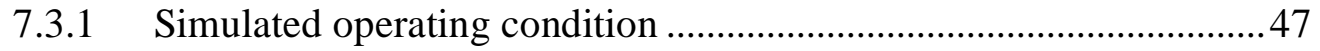

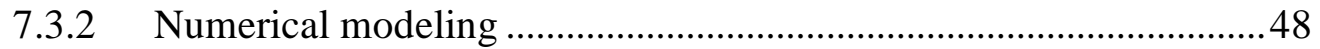

7.3.2.1 Computational grid of 1.9L VW engine .........................48

7.3.2.2 Fuel model ...............................................................49

7.3.2.3 Evaluation of the mechanism for RCCI engine simulation 49

7.3.3 Simulation Setup and Results........................................................50

7.4 Spray Combustion simulation in a Constant Volume Combustion Chamber 53

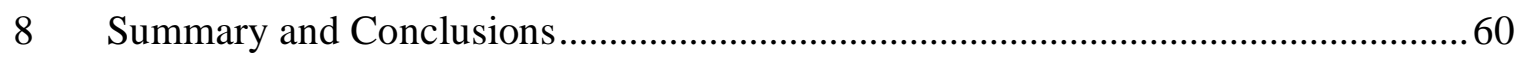

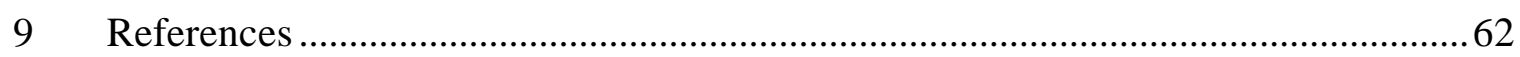




\section{Acknowledgements}

There are many who helped me along the way on this journey. I want to take a moment to thank them.

First, I wish to thank my advisor. Without his guidance, I would not have made it. Professor Youngchul Ra went above and beyond to help me reach my goal. his feedback brought my work to a higher level.

I would like to thank the mechanical engineering department for the opportunity and financial support, the committee members: Professor Agrawal, Professor Naber, and Professor Yang for all the considerate guidance.

I would like to acknowledgment my colleagues at Reacting Flow and Fuel Research Lab: Oudumbar Rajput, Ankith Ullal, Ashwin Purushothaman, Hye JunWon, and Sai Kummar who helped me throughout my Ph.D. research project. I hope to reconnect with each of you.

I would also like to thank my parents: Alimardan and Mansoureh for all the unconditional support, my close friends: Amir, Mamzi, Sanaz, Soroush, Mehdi, Meisam and Kamran, and siblings: Koroush, Shadi, Fatemh and Hanieh for supporting me.

Finally, to my wife, Eleva: your love and understanding helped me through the dark

times. I could not have completed this journey without you especially over the last couple of years and crazy time during Covid-19. 


\section{List of abbreviations}

$\begin{array}{ll}\text { ATDC } & \text { after top dead center } \\ \text { AHRR } & \text { apparent heat release rate } \\ \text { CAD } & \text { Crank angle degree } \\ \text { EVO } & \text { exhaust valve opening } \\ \text { IVO } & \text { Intake valve opening } \\ \text { HCCI } & \text { homogenous charge compression ignition } \\ \text { HRR } & \text { heat release rate } \\ \text { GCI } & \text { gasoline compression ignition } \\ \text { PCCI } & \text { premixed charge compression ignition } \\ \text { RCCI } & \text { reactivity controlled compression ignition } \\ \text { SOI } & \text { start of injection }\end{array}$




\section{Abstract}

A reliable multi-component surrogate fuel model needs to be able to represent both physical properties and chemical kinetics of a real fuel. However, enhancing the fidelity of a model with detailed description of physical and chemical behavior of all fuel components found in real fuels is limited by the prohibitive computational load to calculate the combustion chemistry of the fuel. Hence, it is desirable to achieve computational efficiency by reducing the number of chemical surrogates at the minimum expense of prediction accuracy. The objective of this work is to develop a model that can simulate the oxidation of multi-component fuels by representing the ignition characteristics of physical surrogate components with fewer chemical surrogates and achieve both computational efficiency and prediction accuracy. The main advantage of the model, called the Reactivity-Adjustment (ReAd) combustion model, is to accurately predict the reactivity of the physical surrogate components that the reaction mechanisms of which are not included in the reaction kinetics model employed in the simulation. The reactivity variation of local mixtures with different compositions is modeled by adjusting the reaction rate constants of selected control-reactions in the reaction mechanism of the representative chemical surrogates. An initial version of the model has been developed employing a single chemical surrogate to represent the combustion of diesel fuel which is modeled as multiple surrogate components to capture the physical properties of the real fuel. The model was extended to consider two more chemical surrogate components to represent the ignition characteristics of other chemical families than $n$-alkanes. This enabled to avoid the excessive adjustment of reaction rate constants that were necessary when a single chemical surrogate is used to represent the oxidation kinetics of entire multi-component fuels. The model was extensively tested for simulating oxidation processes of many fuels with a variety of fuel reactivity and in various combustion regimes. The results demonstrated that excellent accuracy of the ignition/combustion prediction was achieved while ensuring computational efficiency. 


\section{Introduction}

Advanced combustion concepts such as PCCI, GCI, RCCI, etc., have shown promising results in terms of thermal efficiency and pollutant reduction in internal combustion (IC) engines [1-3]. In numerical simulations of those advanced combustion engines, more realistic fuel models are required for accurate prediction of the time and location of ignition, which is critical to improve the control strategy of those engines.

In addition, the use of renewable and alternative fuels in conventional IC engines, which shows noticeable environmental and economic benefits, further emphasizes the impact of chemical composition of fuels on combustion and pollutant emissions, and thus more realistic fuel models are required to help understand the combustion characteristics of the fuel and reduce pollutant emissions[4].

Table 1-1 shows the major chemical classes in typical transportation fuels. The contents of chemical classes can vary depending on crude oil composition, refinery process, and even the season when the fuel is produced. Chemical composition can determine all subsequent chemical and physical properties of the fuel. The carbon numbers of the components range approximately from 4 to 12,7 to 18 , and 10 to 20 for petroleumderived gasoline, jet, and diesel fuels, respectively [5].

Typically, transportation fuels consist of up to hundreds of hydrocarbon species, which makes it too costly or impractical to consider all the components that exist in the real fuel into numerical simulation. Therefore, the surrogate fuel models have been developed to better understand the real fuel characteristics.

A surrogate fuel is defined as a fuel composed of a small number of pure compounds whose behavior matches certain characteristics of a target fuel which contains many compounds. A physical surrogate (PS) is used to mimic the relevant physical characteristics of the target fuel like density, volatility parameters, viscosity, surface tension, and diffusion coefficients. Relevant chemical characteristics of the fuel such as ignition behavior, molecular structure, flame speed, and soot propensity are modeled with a chemical surrogate (CS) model [6].

For simplicity, fuels have been represented as a single surrogate component for a long time. For instance, n-heptane is used as the CS fuel of diesel fuel due to its comparable cetane number and heavier hydrocarbons such as dodecane or tetradecane are used as the PS components for diesel fuel [7]. While single surrogate diesel fuel models can provide useful insight, they cannot accurately predict the complex behavior of the vaporization of actual diesel fuel sprays, and thus more deliberate fuel models are required for more accurate ignition and emission predictions. 
Table 1-1: The contents of major chemical classes found in typical transport fuels in U.S. market

\begin{tabular}{|l|l|l|l|}
\hline & Diesel fuel [8] & Gasoline fuel [8] & Jet fuel [5] \\
\hline $\begin{array}{l}\text { normal and iso-alkanes } \\
{[\%]}\end{array}$ & $25-50$ & $35-80$ & $32-65$ \\
\hline cycloalkanes [\%] & $24-40$ & $2-10$ & $20-47$ \\
\hline aromatics [\%] & $15-40$ & $10-44$ & $13-19$ \\
\hline $\begin{array}{l}\text { Others (Incl. olefins) } \\
{[\%]}\end{array}$ & --- & $1-18$ & $2-3$ \\
\hline
\end{tabular}

\subsection{Diesel fuel}

In conventional IC engines, diesel fuel ignites in the non-premixed combustion mode where the representation of the physical properties and the ignitability of the target fuel are key factors in prediction performance. A 2-component surrogate, $\mathrm{n}$-decane and 1methylnaphthalene (1-MN), was formulated as part of Integrated Diesel European Action (IDEA) program to facilitate the comparison between experimental application and numerical simulations. The IDEA fuel has $\mathrm{CN}$, density and $\mathrm{C} / \mathrm{H}$ ratio similar to European \#2 diesel [9].

Myong et al. [10] measured the liquid penetration of evaporating diesel sprays employing a 3-component surrogate diesel (iso-octane, n-dodecane and n-hexadecane) to represent the evaporation characteristics of a target diesel fuel at the low, mid and high boiling points.

Burger at al. [11] compared the entire evaporation characteristic of several surrogate fuels with standard diesel fuels. They measured the distillation curve of four sets of surrogate models from 4-component to 9-component models and compared it with the one from the standard fuels. Among the surrogate models, the one with the lowest number of components (the 4 components surrogate) shows the most dissimilarity to the target diesel fuel with respect to volatility characteristics. They concluded that the number of components in surrogates affects how closely their volatility profiles resemble the real fuel.

Ra et al. [12] studied the vaporization of 6-component surrogate fuel spray in the engine operating conditions. They found that multi-component surrogate fuel models directly affect the vaporization rate and ignition location. They demonstrated that lighter components are more prevalent in the upstream gases of fuel spray, while heavy components are more prevalent downstream. 
Mati et al.[13] used a 5-component mixture to study the oxidation kinetics of synthetic diesel fuel in a jet-stirred reactor. Their surrogate model represents one component in each of the normal, iso and cyclo-alkanes, one alkyl-benzene and one aromatic hydrocarbon to match the amount of various chemical classes in the target fuel.

\subsection{Gasoline and jet fuels}

In conventional IC engines, gasoline fuel burns in the premixed combustion mode where accurate representation of anti-knock tendency of a real gasoline is the key modeling factor. The mixture of iso-octane and n-heptane can represent a wide range of anti-knock tendency of fuels. However, the limitation of $n$-heptane and iso-octane blends in explaining the difference between research octane number (RON) and motor octane number (MON) leads to more complex CS models.

Gauthier et al.[14] used the mixture of iso-octane, toluene, and n-heptane as surrogate for gasoline. They showed that the surrogate model can reproduce the ignition delay times (IDTs) of the real fuel under various temperature, pressure, equivalence ratio and EGR ratio condition, except for rich mixtures at high pressures. Andrae et al.[15] numerically studied a 5-component gasoline surrogate including iso-octane, n-heptane, toluene, diisobutylene and ethanol to model a more realistic gasoline fuel that can predict the nonlinear blending behavior of the MON.

The advantage of direct injection of the fuel in volumetric efficiency increase and possible heat-loss reduction has prompted the direct injection fueling of gasoline. Then similar to diesel fuel, the role of thermophysical properties that affect the mixing of fuel and air becomes more important in direct-injection fueling as it mentioned previously for diesel surrogates. Rajput et al. [16] showed that gasoline can be burnt in a mixingcontrolled or chemically-controlled combustion mode in a 6-stroke engine.

n-Decane has been used as a single surrogate fuel for jet fuel for in chemical kinetic studies since it the average carbon number and the flame structure of jet fuels are similar to those of n-decane [17]. The limitation of a single component in soot emission prediction led to more complex fuel model. Honnet et al. [18] investigated the ignition and soot characteristic of a 2-component jet fuel surrogate model. They used the mixture of n-decane $80 \%$ and 1,2,4-trimethylbenze $20 \%$ by weight as the surrogate of kerosene. Cooke et al. [19]employed a six-component jet fuel surrogate including iso-octane, methylcyclohexane, $\mathrm{m}$-xylene, $\mathrm{n}$-dodecane, tetralin and n-tetradecane in counterflow diffusion flame to study the extinction limits and temperature profile of the flame.

\subsection{Combustion models of multi-component fuels}

While the importance of multi-component fuel models in high fidelity simulation of reactive flows is clear, the application of multi-component fuels in the multi-dimensional simulation of IC engines is mainly limited by the size and availability of the chemical 
reaction mechanism of the selected CS components. For instance, significant research work is devoted to increasing the understanding of oxidation mechanism of n-heptane from early 1970 until today. The recent oxidation kinetic mechanism of $n$-heptane published by Zhang et al. [20] consists of 1268 species and 5336 reactions which is computationally too expensive to be used directly in multi-dimensional simulation of IC engines. Different methods like mechanism reduction techniques [21, 22], and numerical methods [23] for faster chemical kinetics calculations along with models that represent the oxidation kinetics of larger components based on smaller components are used to let us more accurately predict the combustion process in the multi-dimensional simulations of IC engines.

Krishnasamy et al. [24] represent the fuels' physical and chemical properties with two different sets of surrogate components. They validated the surrogate fuel behavior by comparing the hydrogen-to-carbon $(\mathrm{H} / \mathrm{C})$ ratio, cetane index, distillation profile, specific gravity, and lower heating value of their model with experimental data. However, they suggested different CS components to describe the combustion of the fuel. A CS component is used to represent the chemistry of a group of species of the same chemical class and, in this way, fewer CS components are employed than PS components. The model is called the group chemistry representation (GCR) [25]. The simplest GCR approach use a single PS component to represent the chemistry of multi-component fuels. For instance, n-heptane can be selected as the CS component for diesel fuel. The chemical kinetic mechanism of $n$-heptane then be used to model the oxidation kinetics of diesel fuel, while its physical behavior is modeled by using a multi-component model. It is clear that a single component GCR approach is substantially beneficial in terms of computational efficiency at the expense of accuracy.

$\mathrm{Ra}$ and Reitz [26] later extended and improved the multi-component reaction chemistry model to develop the physical surrogate group chemistry (PSGCR) model. In the model, each PS component of a surrogate model has its own chemical reaction mechanism in the form of either detailed reaction pathways or a combination of generic and detailed reaction pathways, and thus the PS components don't need to be grouped into CS components. The consistency between the PS and CS components in the PSGCR model warrants minimal error in multi-component fuel combustion simulations. However, with an increased number of surrogate components in various chemical classes, the overall reaction mechanisms become larger and its application to engine combustion CFD becomes costlier.

It is desirable to have an alternative method to compensate for the reduced accuracy of the GCR approach while maintaining its computational efficiency. In the present study, a method of on-the-fly reactivity adjustment $(\operatorname{Re} A d)$ of the chemical reaction mechanism is presented. In this model, the combustion of PS components is represented by the reaction mechanisms of fewer chemical surrogates, which enables use of smaller reaction mechanisms, and thus save overall computation time. The different reactivity of local mixtures with different compositions is modeled by adjusting the reaction rate constants of selected reactions and re-distribution of the consumption of the individual components 
based on their relative reactivity. The main advantage of the model is to accurately predict the reactivity of PS components that do not have their reaction kinetics mechanisms available or it is computationally expensive to include it in the chemical kinetics calculation. 


\section{Physical surrogate determination method}

Desirably, surrogate fuels have both the same physical and chemical properties as the target fuel. However, it is more likely that either physical or chemical aspects of target fuel properties is more emphasized so that modeling one aspect of the properties is approached first with the other aspect modeled as complementary.

In the present study, the approach is that physical properties are modeled with more emphasis considering the following criteria

- The surrogate fuel captures the evaporation characteristic of the target fuel through a distillation curve comparison.

- The surrogate compositions are substituted with ones that have similar evaporation characteristic to also capture average cetane number and hydrocarbon contents of the target fuel.

- The chemical class contents of the surrogate fuel are in a close agreement with the measured data of the real fuel.

Thus, the chemistry representation of the fuel, which will be discussed later in this paper, is inherently bounded by the selection of the PS components.

\subsection{Physical surrogate representation examples}

The method used to determine the distillation profile and physical properties in multicomponent surrogate fuel is based on the discrete multi-component (DMC) model and the details of the model are provided in [12] . Two surrogate fuels -one for ultra-low sulfur diesel (ULSD) and another for U.S. pump gasoline fuel- are provided to illustrate appropriate models with the above-mentioned criteria.

Four chemical classes of hydrocarbons are considered in the model, including saturates, aromatic, olefins, and oxygenates. Table 2-1 shows the model composition of the 19component surrogate diesel along with the names and boiling temperatures of the surrogate components and Figure 2-1-(a) shows the comparison of the distillation profiles between the measurement and the model prediction.

The model can capture the volatility characteristic of the target fuel well as it is shown in Figure 2-1-(a). (With a maximum error of $4.6 \%$ at the start of distillation). The saturated chemical content of the target diesel fuel is modeled using straight chain, iso, and cycloalkanes; in more detail, 35\%, 36.2\% and $5.8 \%$ of the total fuel's mass are modeled with the straight chain, iso, and cycloalkanes, respectively. The aromatics content modeled using both monocyclic and polycyclic aromatic hydrocarbons (18\% monocyclic and $4.4 \%$ polycyclic aromatics) and olefin content is represented by 1 -octene. As it is shown in the table in Figure 2-1, the chemical contents of surrogate fuel are in excellent 
agreement with the measured data with the maximum error of $0.7 \%$ for aromatic hydrocarbons. The model over-predicts the hydrogen contents by $6.8 \%$ while the carbon contents are under-predicted by $1 \%$. In the model, iso-cetane $\left(\mathrm{iC}_{16} \mathrm{H}_{34}\right)$ represents the largest portion, which is attributed to the component's low volatility and reactivity (cetane number). Adjusting the portions of cetane and iso-cetane allows an effective way to alter the reactivity of the surrogate model while maintaining similar physical properties and distillation curves. 
Table 2-1: 19-component ULSD surrogate model

\begin{tabular}{|l|l|l|}
\hline Fuel component & T-boiling $\left.{ }^{\circ} \mathrm{K}\right]$ & Mass fraction \\
\hline $\begin{array}{l}\text { Methyl-cyclohexane } \\
\text { (MCH) }\end{array}$ & 374.0 & 0.044 \\
\hline 1-Octene & 394.4 & 0.018 \\
\hline Tetramethylhexane & 432.9 & 0.069 \\
\hline n-Decane & 446.9 & 0.034 \\
\hline m-Cymene & 447.7 & 0.019 \\
\hline cis-Decalin & 459.5 & 0.005 \\
\hline n-Hexylbenzene & 475.8 & 0.014 \\
\hline n-Pentylbenzene & 478.2 & 0.034 \\
\hline $\begin{array}{l}\text { Tetralin } \\
\text { n-Dodecane }\end{array}$ & 481.1 & 0.017 \\
\hline Naphthalene & 489.0 & 0.049 \\
\hline n-Tridecane & 507.9 & 0.006 \\
\hline iso-Cetane & 518.9 & 0.031 \\
\hline n-tetradecane & 526.0 & 0.210 \\
\hline $\begin{array}{l}\text { Cetane } \\
\text { n-Octadecane }\end{array}$ & 559.3 & 0.078 \\
\hline Anthracene & 588.8 & 0.174 \\
\hline Eicosane & 612.5 & 0.076 \\
\hline Heneicosane & 629.2 & 0.009 \\
\hline
\end{tabular}




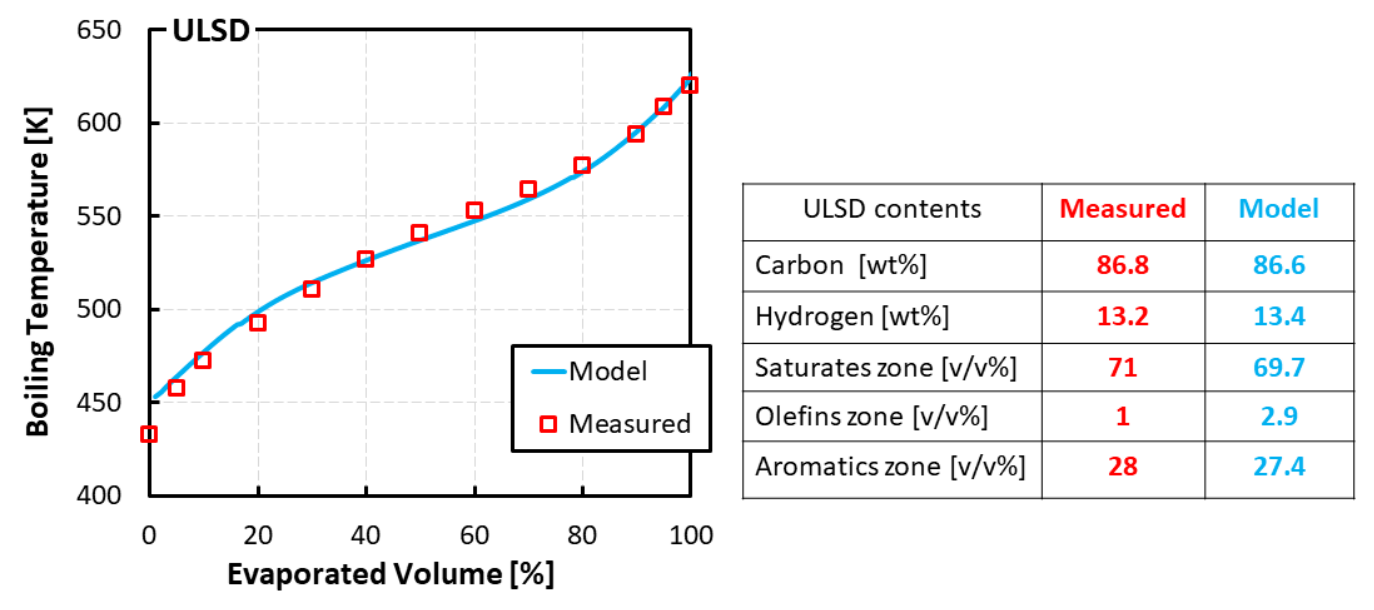

Figure 2-1: Comparison of distillation profile, and fuel contents between the 19component surrogate model in Table 2-1 and ultra-low sulfur diesel (ULSD)

A 13-component surrogate fuel model as shown in Table 2-2 is proposed for pump gasoline fuel with $(\mathrm{RON}+\mathrm{MON}) / 2$ of 89.35 and $0 \%$ ethanol blend. Note that ethanol is a polar component and can change the evaporation characteristics of the fuel significantly. The vaporization model with consideration of non-ideal mixture effects is discussed in [27]. Readers can refer to [28] for a gasoline surrogate with a $10 \%$ ethanol blend. The experimental measurements for this fuel are provided by the Alternative Fuels Engine Lab at Michigan Tech. University. The composition, mass fraction and the corresponding boiling temperature of the 13-component surrogate gasoline is shown in Table 2-2. The model can capture the volatility characteristic of the tested fuel well as it is shown in Figure 2-2.

The chemical contents of the surrogate fuel are compared with the measured data in the table of Figure 2-2. The saturated chemical contents of the tested fuel are modeled using the straight chain, iso, and cycloalkanes; in more detail, $38 \%, 36.5 \%$, and $1.0 \%$ of the total fuel's mass is modeled with straight chain, iso and cyclo-alkanes, respectively. The olefins are represented by 1-octene and 1-pentene and the aromatics content are represented by monocyclic aromatic hydrocarbons. The largest error in the chemical content between the measured and the model is $14.8 \%$ from the olefins content yet the total olefins zone is $5.2 \%$ of the tested fuel. 
Table 2-2: 13-component gasoline fuel surrogate model

\begin{tabular}{|l|l|l|}
\hline Fuel component & T boiling [ $\left.{ }^{\circ} \mathrm{K}\right]$ & Mass fraction \\
\hline Butane & 272.3 & 0.080 \\
\hline iso-Pentane & 300.6 & 0.080 \\
\hline 1-pentene & 302.7 & 0.005 \\
\hline iso-Hexane & 333.0 & 0.040 \\
\hline n-Hexane & 341.5 & 0.125 \\
\hline n-Heptane & 371.1 & 0.175 \\
\hline iso-Octane & 372.0 & 0.110 \\
\hline Methylcyclohexane & 373.4 & 0.010 \\
\hline Toluene & 383.4 & 0.115 \\
\hline 1-Octane & 393.2 & 0.050 \\
\hline iso-Propylbenzene & 425.1 & 0.020 \\
\hline iso-Decane & 433.0 & 0.135 \\
\hline Tetralin & 481.1 & 0.055 \\
\hline
\end{tabular}




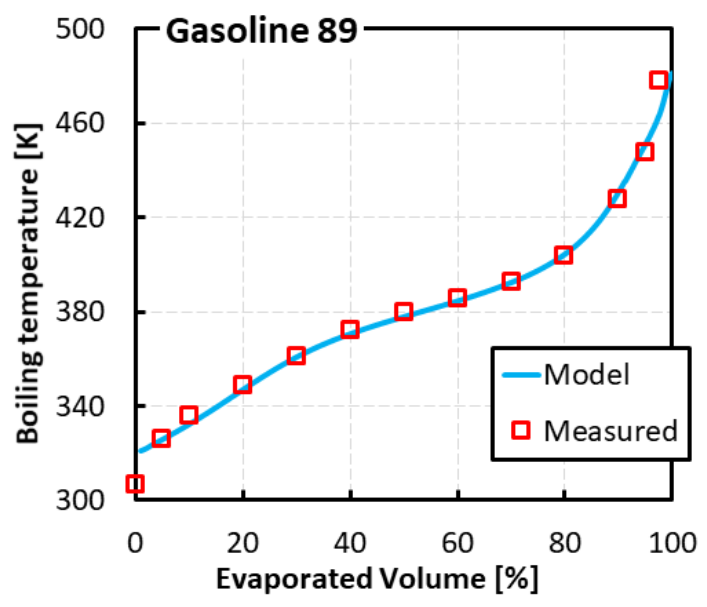

\begin{tabular}{|l|c|c|}
\hline Gasoline-89 contents & Measured & Model \\
\hline Carbon [wt\%] & $\mathbf{8 6 . 2}$ & 86.1 \\
\hline Hydrogen [wt\%] & $\mathbf{1 3 . 7}$ & 13.9 \\
\hline Saturates zone [v/v\%] & $\mathbf{6 9 . 8}$ & 66.8 \\
\hline Olefins zone [v/v\%] & $\mathbf{5 . 2}$ & 5.9 \\
\hline Aromatics zone [v/v\%] & $\mathbf{2 5 . 1}$ & 27.2 \\
\hline
\end{tabular}

Figure 2-2: Comparison of distillation profile and fuel contents between the 13component surrogate model in Table 2-2 and pump gasoline 89 fuel 


\section{Computational tools}

Numerical simulations are performed using an in-house computational fluid dynamics (CFD) code that is based on KIVA-3V r2, and coupled with various advanced physical sub-models to account for multi-component fuels properties, spray physics, turbulent mixing, and detailed chemistry calculations [29].

A hybrid primary spray break-up model that is computationally efficient as well as comprehensive enough to account for the effects of aerodynamics, liquid properties and nozzle flows was employed. In this model, the injected fuel "blobs" are tracked by a Lagrangian method while the break-up of each blob is calculated from considerations of jet stability from Kelvin-Helmholtz $(\mathrm{KH})$ instability theory. For the secondary and further break-up processes, a Kelvin Helmholtz $(\mathrm{KH})$ - Rayleigh Taylor (RT) hybrid model was used [30].

A droplet collision model based on the stochastic particle method was used, in which the collision frequency is used to calculate the probability that a drop in one parcel will undergo a collision with a drop in another parcel, assuming all drops in each parcel behave in the same manner. The probability of coalescence is determined considering the Weber number that includes the effects of density and surface tension of the liquid droplets [29] .

Droplet deformation in terms of its distortion from sphericity is modeled using a forced, damped harmonic oscillator model, where the surface tension and viscosity of the droplet are the major properties used in the restoring force and damping terms, respectively [31]. Distortions of the droplets affect the momentum exchange between the droplets and the ambient gas, and subsequently the drop velocities (or relative velocity between the drop and the gas) that are the governing parameters in the breakup and evaporation processes.

The droplet vaporization model considers the evaporation of spray droplets using the Discrete Multi-Component (DMC) approach under temperatures ranging from flashboiling conditions to normal evaporation. The improved model accounts for variable internal droplet temperatures and considers an unsteady internal heat flux with internal circulation, and a model for the determination of the droplet surface temperature. The model uses an effective heat transfer coefficient model for the heat flux from the surrounding gas to the droplet surface. The effective heat transfer coefficient calculated in the model is also used to determine the amount of fuel to be treated as vapor when the drop surface temperature reaches the critical temperature while the drop interior is still in the sub-critical condition. The model has been well tested for evaporation of sprays as well as single drops at various pressure and temperature conditions including flashboiling.

For the turbulence calculation, the RNG k- $\varepsilon$ model [32] was used . In the two-phase transport equations, droplets are treated as point sources and the physical dimension of the droplets is not resolved on the gas-phase computational grid. Therefore, it is assumed 
that the vaporized fuel in a computational cell where droplets exist mixes completely with the gaseous mixture within the cell. Thus, stratification of gaseous species within a single cell is not resolved. The fuel species mass fraction and gas temperature in the dropcontaining cells is used as the boundary conditions for the mass and energy balance equations to be solved in the present vaporization model. The physical models employed in the present study have been extensively validated for diesel spray injections.

In this study, the chemistry solver was integrated into the CFD code. The role of chemistry solver is to find $\frac{d Y_{k}}{d t}$ based on the provided reaction mechanism, where $Y_{k}$ is the mass fraction of species $k$. In the current CFD code, the gas-phase solution procedure is based on a finite volume method called the arbitrary Lagrangian-Eulerian (ALE) method. In ALE method each cycle (i.e., each time step) is divided into a Lagrangian phase and rezone phase. In the Lagrangian phase the cell vertices move with the fluid velocity and there is no convection cross cell boundaries. In the rezone phase, the flow field is frozen, and the vertices are moved to the user-specified positions. It is reasonable to assume each computational cell is like a closed volume reactor for chemistry calculation in each cycle before rezone phase.

For a reaction mechanism that has $n_{r}$ of reactions and $n_{s}$ of species, the rate of change of mass fraction in a constant volume reactor that density $(\rho)$ is constant is given by

$$
\frac{d Y_{k}}{d t}=\frac{W_{k} \omega_{k}}{\rho}
$$

which leads to $n_{s}$ equations for the aforementioned reaction mechanism. Note that $\omega_{k}$ which is called the production rate is a function of temperature and the above ODEs (Eq.3-1) need a closure equation for rate of change temperature $\left(\frac{d T}{d t}\right)$. This equation is provided based on energy equation for an adiabatic constant-volume reactor.

In the current CFD code, the chemical kinetics calculation is done with parallel CPU computing in message passing interface (MPI) environment. The necessary information like pressure, density, initial temperature, CFD timestep (as chemistry integration time for ODE), etc., are passed to the chemistry solver and in turn species mass fraction are calculated by the chemistry solved and passed to the CFD code.

It should be noted that in chemical kinetics problems as production and consumption of species are substantially different, the above ODEs led to a stiff ODE system. While there are different options for stiff ODE systems in the code, all the CFD results in this work are obtained based on the SpeedCHEM solver [33] with the LSODE solver. Note that as temperature-dependent functions like the rate of reaction, $K(T)$, in SpeedCHEM solver are tabulated. Therefore, the adjustment of reaction rate constants that is required in the current model and discussed in Chapter. 4 need to alter the rate of reactions, not the pre-exponential coefficient. 
The IDTs calculation for homogenous mixtures are performed using CHEMKIN PRO [34] in order to save computation time since it was confirmed that the results obtained by the in-house CFD code are almost identical to those of CHEMKIN calculation. Note that the simulated IDTs in this work are defined as the time lapsed to increase the mixture temperature by $400 \mathrm{~K}$ from the initial temperature [35]. 


\section{Model formulation (Chemical kinetics representation)}

In the present model, the combustion kinetics of PS components is represented by the reaction mechanisms of fewer CS components. These CS components are referred to as base-CS components and the consumption of the PS components at each time step is modeled using the reaction mechanism of base-CS components. The reaction rate constants of selected reactions are adjusted to capture the total consumption of PS components that are grouped together and assigned to a base-CS in each time step. This method is referred as on-the-fly reactivity adjustment and described in Section.4.2. The share of each PS component in the total consumption is also modeled based on the relative reactivity of PS components and considered when the grouped PS components are re-distributed back to individual PS component. This model will be described in Section.4.3.

It is desirable to keep the number of base-CS components as small as possible in order to reduce the size of the chemical reaction mechanism. In the first attempt [36], n-heptane was selected as a single base-CS component and combustion of a multi-component diesel fuel is represented by the chemistry of the base CS. However, capturing the lowtemperature $(T<850)$ combustion of the multi-component fuel accurately requires excessive tuning of reaction rate constants of multiple reactions. This is because the multi-component target fuel contains fuel components in other chemical classes than $\mathrm{n}$ alkanes, which have substantially different oxidation characteristics from those of $n$ alkanes. Hence, the model was extended to include two more base-CS components, isooctane and toluene, in order to avoid tuning of reaction rate constants. The addition of these base-CS components enables to accurately take into account the effect of highly branched alkanes and low reactivity aromatic hydrocarbons in low-temperature combustion.

\subsection{Mixture relative reactivity index}

It is known that the IDTs of fuel is inversely proportional to the reactivity of the fuel. Ra and Reitz [26] developed an index of reactivity, called relative reactivity index (RRI), that is calculated from the IDT using a simple formulation as

$$
R R I=\frac{a}{\tau_{c}}+b
$$

where $\tau_{\mathrm{c}}$ is the characteristic IDT in milliseconds for a reference initial conditions of a stoichiometric mixture at $40 \mathrm{bar}$ and $850 \mathrm{~K}$ in a constant volume chamber, and $\mathrm{a}$ and $\mathrm{b}$ are two model constants for the chemical class of the fuel. They showed that the RRI correlates linearly with the cetane number of the fuel, i.e., $\mathrm{RRI} \cong \mathrm{CN}$. For example, the calculated RRI of straight-chain alkanes are very similar to their cetane numbers [37] over the fuel's carbon number variation between 3 and 20, as shown in Figure 4-1. 


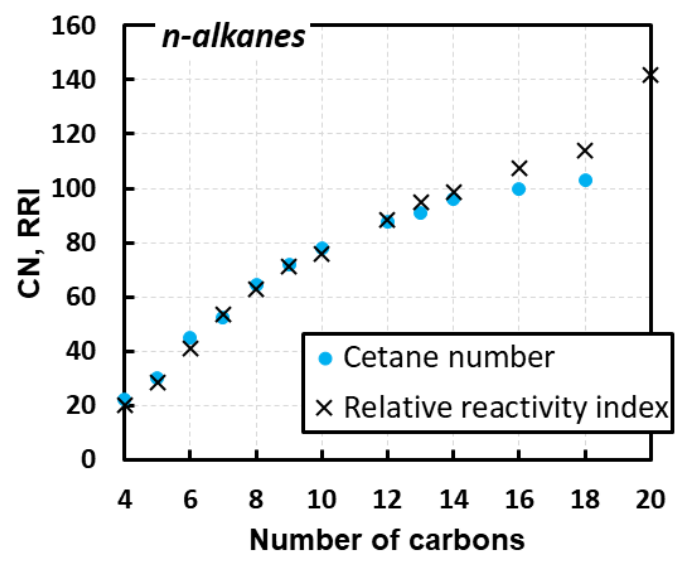

Figure 4-1: Comparison of relative reactivity index and cetane number for n-alkanes fuels

The RRI of a local mixture, $R R I_{m}$, is defined as the mass-average of the individual fuel components contained in the mixture, and obtained as,

$$
R R I_{m}=\sum Y_{i} R R I_{i}
$$

where $Y_{i}$ and $R R I_{i}$ are mass fractions and RRI of species $i$, respectively. For the extended model that considers multiple CS components, the equation is modified to consider grouping of PS components to

$$
R R I_{m, j}=\sum_{i=1}^{N_{j}} Y_{i, j} R R I_{i}
$$

where $R R I_{m, j}$ is the average RRI of the $\mathrm{j}^{\text {th }} \mathrm{CS}$ group in the mixture, $N_{j}$ and $Y_{i, j}$ are the number of components considered and the mass fraction of component $i$ in the jth CS group, respectively. The $R R I_{m, j}$ is used to improve the prediction of consumption rate of grouped fuels. The methods on how $R R I_{m, j}$ is used before and after chemical kinetic calculation to improve the prediction accuracy is explained in Section.4.2 and 4.3.

\subsection{On-the-fly reactivity adjustment (ReAd) model}

In general, it is expected that high reactivity fuels are consumed faster than lower reactivity fuels. When the number of CS components is less than that that of PS component, CS components represent a group of PS components- typically according to the PS components' chemical classes- assuming that the characteristics of oxidation processes are modeled by the chemical kinetics of the CS component. Without 
considering the difference in the reactivity of the individual components in the group, the consumption rate of a CS component is regarded to be equal to the average consumption rate of the group. As mentioned above, in the present model, the reaction rate constants of selected reactions are adjusted based on local reactivity to capture the consumption rate of grouped fuels.

The correlations for reactivity adjustment were built from the IDTs of reference fuels which have their reaction kinetics mechanisms and CNs. Note that the reference fuels in this study are based on database by Ra and Reitz [26] which has 56 fuels in 7 chemical classes. The reactivity adjustment of the base-CS components is achieved by changing reaction rate constants of selected reactions, called 'control reactions', in the reaction mechanism. For each reference fuel, the reaction rate constants of the control reactions are adjusted to match the IDTs predicted by the reference fuel's own reaction mechanism under the reference conditions. Detailed procedure is described below.

Step1: Perform ignition delay sensitivity analysis to determine control reactions of the base-CS components. The pre-exponential factor of a reaction is varied and its sensitivity on ignition delay times is calculated.

Step 2: Find the amount of adjustment of the pre-exponential factors of the control reactions to match the ignition delay times of the target reference fuel under reference conditions. The reference conditions are defined as range of initial temperature of $700 \mathrm{~K}$ to $1300 \mathrm{~K}$ for a stochiometric mixture at initial pressure of $40 \mathrm{bar}$.

Step 3: Build correlations for adjustment amount of pre-exponential factors of control reactions as a function of RRI of the reference fuels.

Step 4: Repeat Steps 1-3 for different equivalence ratio and pressure in order to incorporate the different impact of those parameters on the reference fuels in the correlations.

The reaction kinetics of the reference fuels are based on the work by Ra et. al. [25, 26]. The reaction mechanisms have been extensively validated against experimental data such as shock tube tests, rapid compression machine, HCCI engine, and CVCC spray combustion experiments available in the literature. In Section.4.4, detailed procedure to apply the above-mentioned steps to a base-CS component, n-heptane, to represent the reactivity of $n$-alkanes reference fuels are provided.

\subsection{Reactivity-based re-distribution of fuel components}

Global one-step reaction equation for the combustion of a stoichiometric non-oxygenated hydrocarbon fuel/air can be written as: 


$$
\begin{gathered}
N_{s t} C_{x} H_{y}+N_{s t}\left(x+\frac{y}{4}\right)\left(O_{2}+3.76 N_{2}\right) \\
\rightarrow N_{s t} x C O_{2}+N_{s t} \frac{y}{2} H_{2} O+N_{s t}\left(x+\frac{y}{4}\right)(3.76) N_{2}
\end{gathered}
$$

where $N_{s t}$ is the number of moles of fuel in the stoichiometric mixture. The consumption rate of fuel can be approximated using a characteristic time, $\tau_{c}$, as

$$
\frac{d N_{f}}{d t} \sim \frac{N_{s t}}{\tau_{c}}
$$

Taking the IDT as the characteristic time and using fuel mole fraction, $x_{s t}$, for $N_{s t}$, Eq. (4-5) becomes

$$
\frac{d N_{f}}{d t} \cong \frac{\Delta N_{f}}{\Delta t}=k \frac{x_{s t}}{t_{i g}}
$$

where $k$ is a proportionality constant to make the equation. Therefore, the mass consumption of fuel is obtained as

$$
\frac{\Delta m_{f}}{\Delta t}=M W_{f} k \frac{x_{s t}}{t_{i g}}
$$

For a multi-component fuel, the same equation can be applied, i.e.,

$$
\frac{\Delta m_{i}}{\Delta t}=M W_{i} k \frac{x_{s t, i}}{t_{i g, i}}
$$

Or

$$
\Delta m_{i}=M W_{i} k \frac{x_{s t, i}}{t_{i g, i}} \Delta t
$$

And the total consumption of fuel, $\Delta m_{T}$, is obtained from the sum of the consumption of the individual components.

$$
\Delta m_{T}=\sum \Delta m_{i}=k \Delta t \sum M W_{i} \frac{x_{s t, i}}{t_{i g, i}}
$$

Or

$$
k \Delta t=\frac{1}{\sum M W_{i} \frac{x_{s t, i}}{t_{i g, i}}} \Delta m_{T}
$$


Inserting $k \Delta t$ of Eq. (4-9)into Eq. (4-8), the consumption of individual component is obtained as

$$
\Delta m_{i}=\frac{M W_{i} \frac{x_{s t, i}}{t_{i g, i}}}{\sum M W_{i} \frac{x_{s t, i}}{t_{i g, i}}} \Delta m_{T}
$$

Note that $\Delta m_{T}$ is calculated using the reaction mechanism of a base-CS component and the reactivity of a local mixture, $R R I_{m, j}$. Then the consumption fractions of individual components obtained from Eq. (4-10) are used to update the amount of grouped PS components. This model is referred as the re-distribution model in the present work.

\subsubsection{Prediction of the reaction rate of local mixture}

For a local mixture that is assumed to be well-mixed, the average reactivity $R R I_{m, j}$ is calculated for each base-CS component. The total consumption $\Delta m_{T}$ is calculated using the reaction mechanism of the base-CS component with reactivity adjustment as explained in Section.4.2. Then the consumption of individual PS components, $\Delta m_{i}$, are calculated using Eq. (4-10). This process is repeated at every time-step. Note that the value of $k$ is unknown in Eq. (4-7), although the re-distribution of individual components can be obtained using Eq. (4-10) regardless of the constant $k$ as long as it is assumed $k$ is the same for all grouped-fuel components. However, the $k$ can be estimated from the fuel consumption rates of the previous time steps. It is reasonable to assume that the fuel consumption rates of adjacent time steps change gradually and slowly if the time steps are small enough. Rearranging Eq. (4-9) for $k$ gives

$$
k=\left(\frac{\Delta m_{T}}{\Delta t}\right) /\left(M W_{f} \frac{x_{s t}}{t_{i g}}\right)
$$

The values $k$ of the previous two time-steps and their difference can be used to estimate the $k$ of the current time step to predict the consumption rates of fuel components even before chemical kinetics calculations. This predicted reaction rates can be employed to improve the estimation of the $R R I_{m, j}$ that contains intermediate species, too.

\subsection{Base-CS component for n-alkanes}

In this section, the 4 aforementioned steps (see Section.4.2) for the reactivity adjustment (ReAd) model is explained in detail for a base-CS component for n-alkanes. n-Heptane is selected as the base-CS component due to its reactivity comparable to diesel fuels, availability of comprehensive reaction mechanisms and extensive studies on its autoignition process. $\mathrm{n}$-Heptane is a straight-chain alkane (n-alkane) and its ITDs shows a negative temperature coefficient (NTC) region (typically $\mathrm{T}<1000 \mathrm{~K}$ ) at IC engine relevant operation pressures (20bar $<\mathrm{P}<40 \mathrm{bar}$ ) [38-40]. The reaction kinetics 
mechanisms for the base-CS components employed in the present work are available in Ref .[41], and are explained briefly here.

The reaction kinetics mechanisms of base-CS components used in the present study are reduced mechanisms. The comprehensive mechanism of $n$-heptane from the Lawrence Livermore National Laboratory (LLNL) [42] was used to generate a reduced mechanism. Isomer lumping along with pathway reduction are applied in the reduction process. The major reaction pathways in the comprehensive mechanism were retained in the reduced mechanism based on their rank of importance.

The n-alkanes with a carbon number of 4 to 20 were selected as the reference fuels for the n-heptane-based ReAd model. Note that n-alkanes lighter than n-butane $\left(\mathrm{C}_{4} \mathrm{H}_{10}\right)$ are excluded from the reference fuels as their ignition characteristic are noticeably different from the larger n-alkanes, especially at low temperatures. However their reaction kinetics mechanisms are available as sub-mechanisms of n-heptane mechanism. The simulated IDTs of C4 to C18 n-alkanes are shown in Figure 4-2. All the reference fuels show the NTC behavior at around $850 \mathrm{~K}$, which is in good agreement with detailed kinetics studies[43, 44]. Meanwhile, it is well-understood that the reactivity of n-alkanes increases with increasing carbon number.

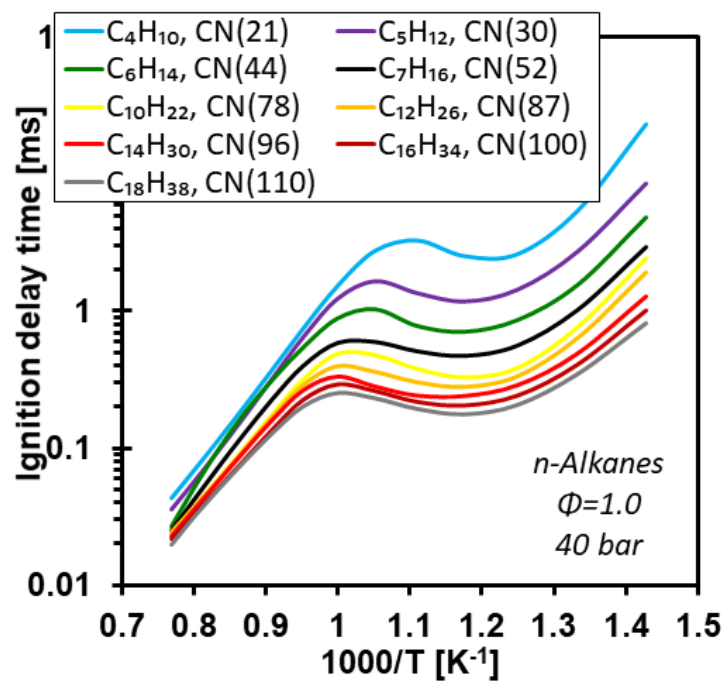

Figure 4-2: comparison of simulated IDTs of n-alkanes/air mixture based on the reference chemical reaction mechanism used in this study 


\subsubsection{Selection of control reactions of $n$-heptane mechanism}

The pre-exponential factors of selected reactions (control reactions) of the n-heptane reaction mechanism are adjusted such that the IDTs at the RRI reference conditions $(\mathrm{T}=850 \mathrm{~K}, \mathrm{P}=40$ bar, $\varphi=1$ ) match those of reference fuels with a known RRI.

The choice of the control reactions was made though the IDT curve sensitivity analysis [25]. The reactions with the highest ranks in sensitivity at low to intermediate temperatures including the NTC region are selected as the control reactions. The four control reactions selected for the current mechanism of n-heptane are:

$$
\begin{gathered}
n \mathrm{C}_{7} \mathrm{H}_{16}+\mathrm{HO}_{2} \leftrightarrow \mathrm{C}_{7} \mathrm{H}_{15-2}+\mathrm{H}_{2} \mathrm{O}_{2} \\
\mathrm{C}_{7} \mathrm{H}_{15} \mathrm{O}_{2} \leftrightarrow \mathrm{C}_{7} \mathrm{H}_{14} \mathrm{OOH} \\
\mathrm{C}_{7} \mathrm{H}_{14} \mathrm{OOH}+\mathrm{O}_{2} \leftrightarrow \mathrm{O}_{2} \mathrm{C}_{7} \mathrm{H}_{14} \mathrm{OOH} \\
n \mathrm{C}_{7} \mathrm{H}_{16}+\mathrm{O}_{2} \leftrightarrow \mathrm{C}_{7} \mathrm{H}_{15-2}+\mathrm{HO}_{2}
\end{gathered}
$$

The variation of the IDT curves of the above reactions is shown in Figure 4-3. In the figure, $A_{c-1} \times 10$ indicates that the pre-exponential factor of the control reaction $\mathrm{C}-1$ is multiplied by 10 . Control reaction $\mathrm{C}-1$, which is a hydrogen abstraction reaction by the hydroperoxyl radical, affects IDTs at both high and intermediate temperatures, while reaction $\mathrm{C}-2$, which is an isomerization reaction, mainly affects IDTs at low and intermediate temperatures. The control reaction $\mathrm{C}-3$, which is the second peroxidation reaction in the degenerate branching process, mainly affects IDTs at intermediate temperatures.

A combination of adjustment of C-2 and C-3 control reactions enables to capture the reactivity of $n$-alkanes with higher reactivity than $\mathrm{n}$-heptane $\left(\mathrm{RRI}_{\mathrm{nC} 7 \mathrm{H} 16} \approx \mathrm{CN}=52.5\right)$. For example, to capture the reactivity of n-octane $\left(\mathrm{RRI}_{\mathrm{nC} 8 \mathrm{H} 18} \approx \mathrm{CN}=64.5\right)$, the preexponential factors of reactions C-2 and C-3 are increased to shorten the IDTs, matching those obtained from the reaction mechanism of n-octane as well as n-octane RRI. (refer to Eq. (1)) In order to match the IDTs of reference fuels at high temperatures, C-1 control reaction is adjusted together with $\mathrm{C}-2$ control reaction. The extent of adjustment of the pre-exponential factor of the control reactions is formulated as correlations with respect to the reactivity (RRI) of the local fuel/air mixtures. To improve the accuracy of the correlations, the application ranges of the correlations were divided into three reactivity ranges; i) reactivity higher than cetane, ii) reactivity between cetane and n-heptane, and iii) reactivity lower than $n$-heptane. For each range, the number of control reactions and their adjustment correlations were developed. 


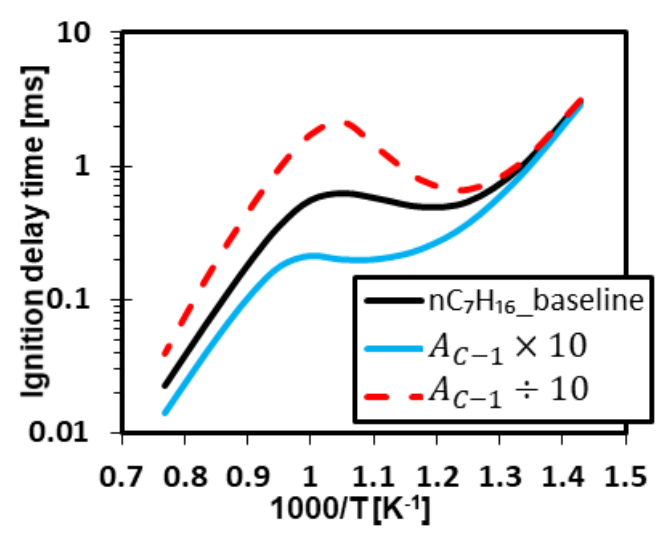

(a)

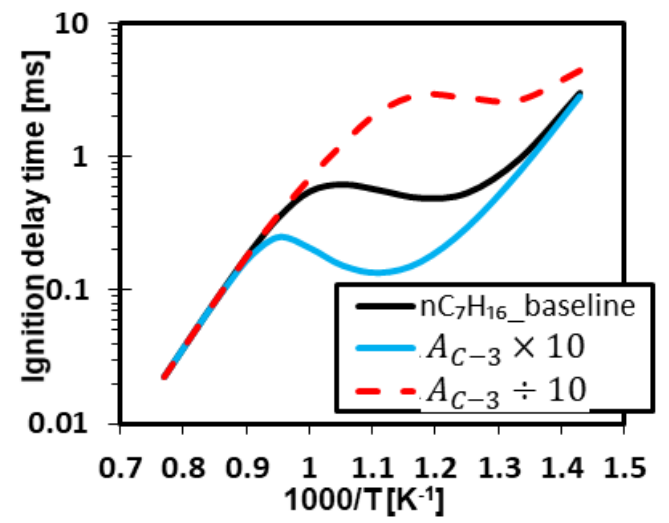

(c)

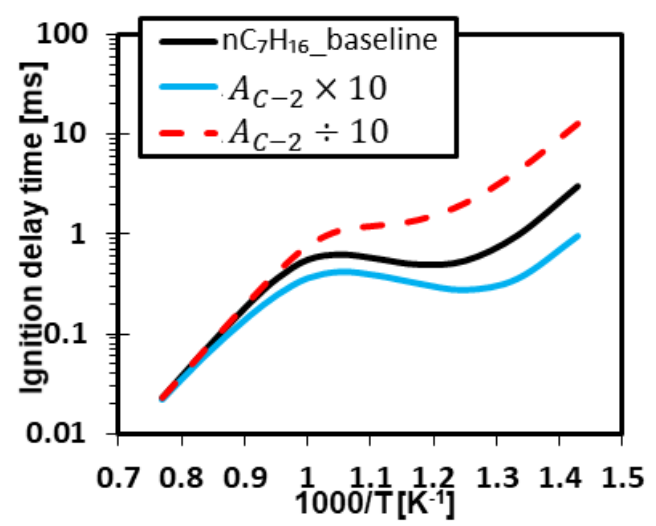

(b)

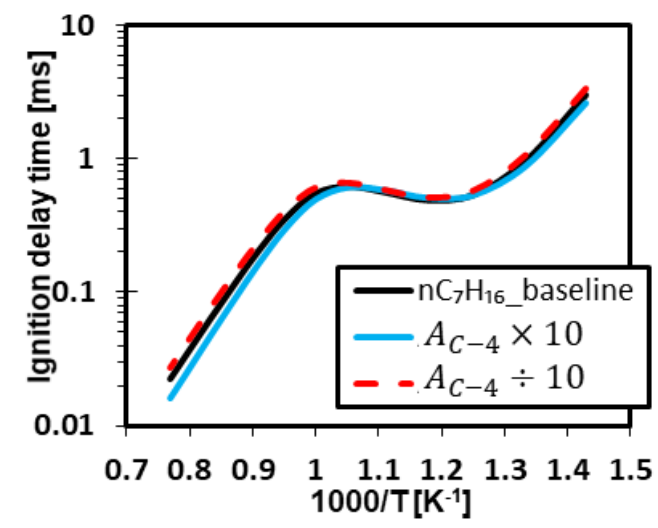

(d)

Figure 4-3: Sensitivity of ignition delay curve of $n$-heptane mechanism (a) reaction $\mathrm{nC}_{7} \mathrm{H}_{16}+\mathrm{HO}_{2}=\mathrm{C}_{7} \mathrm{H}_{15-2}+\mathrm{H}_{2} \mathrm{O}_{2}$, (b) reaction $\mathrm{C}_{7} \mathrm{H}_{15} \mathrm{O}_{2}=\mathrm{C}_{7} \mathrm{H}_{14} \mathrm{OOH}$, (c) reaction $\mathrm{C}_{7} \mathrm{H}_{14} \mathrm{OOH}+\mathrm{O}_{2}=\mathrm{O}_{2} \mathrm{C}_{7} \mathrm{H}_{14} \mathrm{OOH}$, (d) reaction $\mathrm{nC}_{7} \mathrm{H}_{16}+\mathrm{O}_{2}=\mathrm{C}_{7} \mathrm{H}_{15-2}+\mathrm{HO}_{2}$

The correlations of adjustment factor, $S_{f}$, of the control reactions for the different reactivity ranges are shown in Table 4-1. The adjustment factors obtained from the correlations are multiplied to the existing pre-exponential factors of the control reactions. 
Table 4-1: Correlation of adjustment factor, $\mathrm{S}_{\mathrm{f}}$, for control reactions C-1, C-2, C-3 and C4

\begin{tabular}{|c|c|c|}
\hline $\begin{array}{l}\text { Mixture } \\
\text { reactivity }\end{array}$ & Adjustment factor & \\
\hline \multirow[t]{2}{*}{$\begin{array}{l}\text { Higher than } \\
\text { n-heptane }\end{array}$} & $\begin{aligned} \begin{aligned} S_{f, H}(C-2)= & a_{21} R R I_{m, 1}^{3}+b_{21} R R I_{m, 1}^{2}+c_{21} R R I_{m, 1} \\
& +d_{21}\end{aligned} & \\
a_{21}= & 1.927 \mathrm{E}-4 \\
b_{21}= & 6.280 \mathrm{E}-2 \\
c_{21}= & -6.384 \\
d_{21}= & 209.9\end{aligned}$ & $(4-12)$ \\
\hline & $\begin{array}{l}S_{f, H}(C-3)=a_{31} R R I_{m, 1}^{3}+b_{31} R R I_{m, 1}^{2}+c_{31} R R I_{m, 1}+ \\
d_{31} \\
a_{31}=3.015 \mathrm{E}-5 \\
b_{31}=-8.270 \mathrm{E}-3 \\
c_{31}=7.746 \mathrm{E}-1 \\
d_{31}=-23.0\end{array}$ & $(4-13)$ \\
\hline \multirow{3}{*}{$\begin{array}{l}\text { Higher than } \\
\text { cetane }\end{array}$} & $S_{f, H}(C-2)=0.037 R R I_{m, 1}+0.981$ & $(4-14)$ \\
\hline & $S_{f, H}(C-3)=0.007 R R I_{m, 1}+1.880$ & $(4-15)$ \\
\hline & $S_{f, H}(C-4)=0.347 R R I_{m, 1}-25.0$ & $(4-16)$ \\
\hline $\begin{array}{l}\text { Lower than n- } \\
\text { heptane }\end{array}$ & $\begin{array}{l}S_{f, L}(C-1)=a_{11} R R I_{m, 1}^{3}+b_{11} R R I_{m, 1}^{2}+c_{11} R R I_{m, 1}+d_{11} \\
a_{11}=-2.981 \mathrm{E}-4 \\
b_{11}=4.030 \mathrm{E}-2 \\
c_{11}=-1.851 \\
d_{11}=30.352\end{array}$ & $(4-17)$ \\
\hline
\end{tabular}




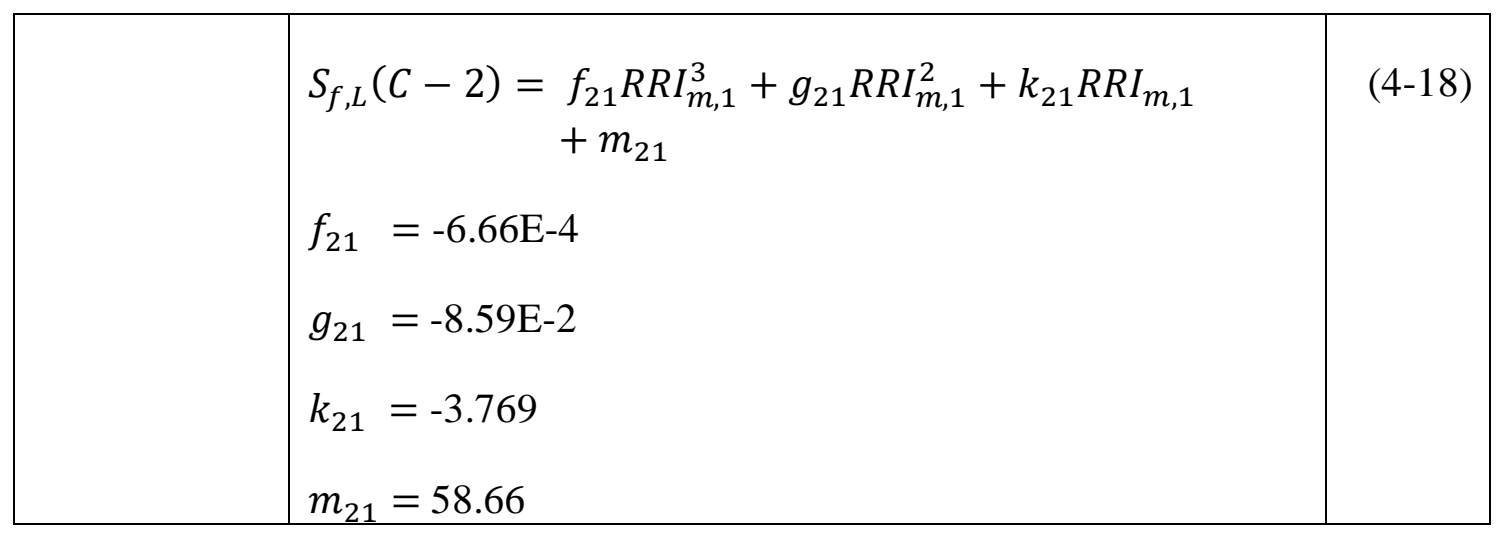

\subsubsection{Effect of equivalence ratio on reactivity adjustment}

The present ReAd model takes into account the effect of mixture equivalence ratio in the formulation of the reactivity adjustment. Figure 4-4 shows the performance of the ReAd model applied to simulate n-butane reactivity with and without considering the effect of equivalence ratio in reactivity adjustment correlations. The simulations were performed for lean, stoichiometric, and rich mixtures of n-butane in a constant volume reactor and an initial pressure of 40 bar. The IDTs obtained using the chemical reaction mechanism of reference fuels are plotted for comparison as well. It is seen that the ReAd model performs well for the stoichiometric mixture without considering the mixture equivalence effect. However, the performance of the model in the cases of lean and rich mixtures is not as good as the stoichiometric mixture cases, as shown in Figure 4-4-(a),(b). The ReAd model under-predicts the IDTs at low temperatures $(700-850 \mathrm{~K})$ for the lean mixtures. On the contrary, it over-predicts the IDTs of rich mixtures. Similar behavior is observed for lower reactivity fuels than n-heptane, such as n-pentane and n-hexane. 

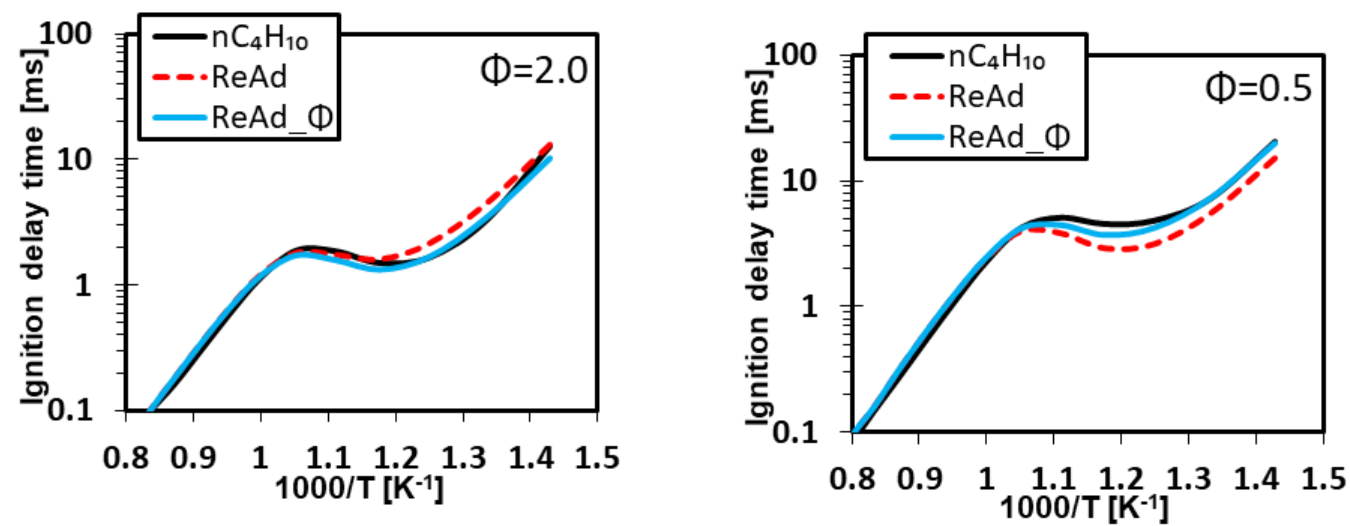

(a)

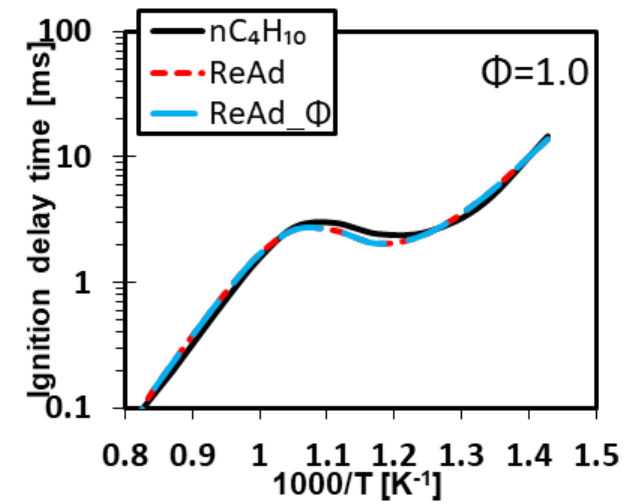

(b)

(c)

Figure 4-4: Comparison of simulated IDTs of n-butane for a (a) rich (b) lean (c) stoichiometric in a CV reactor. Solid-black lines -the reference fuels mechanism, dash-red lines -the ReAd model without considering the effect of equivalence ratio, and solid-blue lines -with considering the effect of equivalence ratio

To formulate the effect of equivalve ratio in the adjustment correlations, the IDTs of neat low-reactive fuels like $n$-hexane and $n$-heptane with equivalence ratios of $0.5,0.75,1.0$, $1.5,2.0$, and 2.5 were calculated. Using them as the reference values, further adjustment of $S_{f}$ of the control reactions was made to reduce the error within the tolerance for all equivalence ratio conditions tested. It was found that the change of the control reaction C-2 only would be enough to meet the error tolerance without adjusting the other control reactions. The adjustment is expressed as a multiplication factor in a form of third order polynomial function by normalizing the adjustment with those for the stoichiometric mixtures. Eq. (4-19) shows the multiplication factor for the equivalence ratio effect that is applied to $\mathrm{C}-2$ control reaction.

$$
S_{f, L}(C-2)=S_{f, L}(C-2)^{\text {Table } 2} \cdot\left(-a_{1} \Phi^{3}+a_{2} \Phi^{2}-a_{3} \Phi+a_{4}\right)
$$


where the $S_{f, L}(C-2)^{\text {Table } 2}$ is the value of the $S_{f, L}(C-2)$ presented in Table 4-1, and $a_{1} a_{2}, a_{3}$ and $a_{4}$ are the coefficients of the equivalence ratio adjustment, which are obtained from RRI of the local mixture using the equations shown in Table 4-2.

Table 4-2: The correlation for $\mathrm{a}_{1}, \mathrm{a}_{2}, \mathrm{a}_{3}$, and $\mathrm{a}_{4}$ coefficients that are used in Eq.(4-19)

\begin{tabular}{|c|c|}
\hline$a_{1}=0.0003 R R I_{m, 1}+0.2421$ & (20) \\
\hline$a_{2}=-0.0022 R R I_{m, 1}+1.3891$ & (21) \\
\hline$a_{3}=-0.0168 R R I_{m, 1}+2.9059$ & (22) \\
\hline$a_{4}=-0.0168 R R I_{m, 1}+2.9059$ & (23) \\
\hline
\end{tabular}




\section{Extension of the model using more base-CS components}

The IDT curves of 19-component surrogate diesel are shown along with $n$-heptane in Figure 5-1 for mixtures of three different equivalence ratios at an initial pressure of 40 bar. The mole-averaged $\mathrm{CN}$ of 19-component surrogate fuel $(\mathrm{CN} \sim 56.9)$ is comparable to that of the $n$-heptane $(\mathrm{CN}=52.5)$. It is seen that the IDTs of the multi-component fuel at low-temperatures $(\mathrm{T}<850 \mathrm{~K})$ are much shorter than those of $\mathrm{n}$-heptane. This characteristic difference of the two fuels in low temperature reactivity is attributed to the effects of combined oxidation of components in multiple chemical classes including aromatics and branched-alkanes. By choosing more control reactions of a single-CS mechanism, this discrepancy at low temperatures can be alleviated for a certain target multi-component fuel [36]. However, the limitation of this approach is that the number of additional control reactions as well as their adjustment factors vary not only for different multicomponent fuels, but also at different mixture equivalence ratios (see Figure 5-1-(b)). This problem can be addressed by employing more base-CS components to represent the characteristics of reactivity variation of different chemical classes.

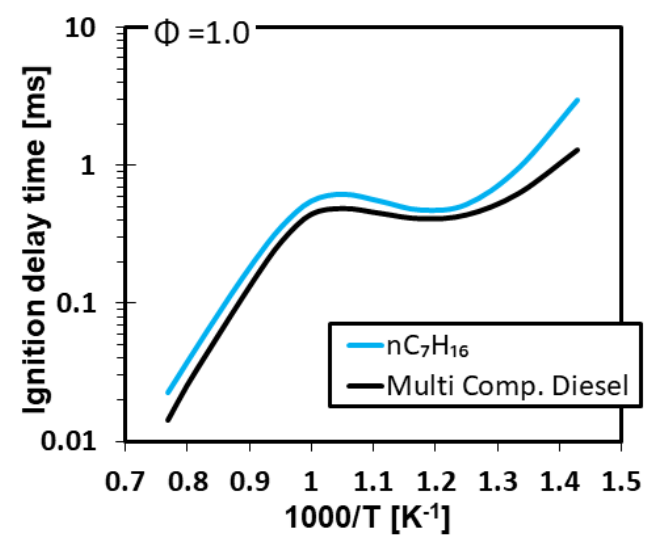

(a)

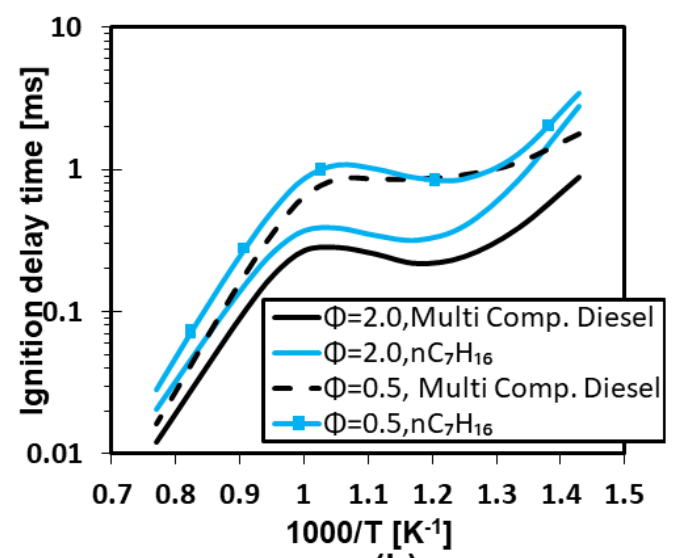

(b)

Figure 5-1: Comparison of simulated IDTs of n-heptane and the 19-component ULSD (Table 2-1 ) for a (a) stoichiometric, and (b) lean and rich mixtures in a CV reactor with an initial pressure of 40 bar

Along with normal alkanes, iso-alkanes are major contents of diesel and gasoline fuels available in North America $[9,45]$. Since these two chemical classes have substantially different reactivity from n-alkanes, it is desirable to model the iso-alkanes with a different base-CS component in order to improve the accuracy of the ReAd model.

One characteristic of iso-alkane oxidation kinetics is that, compared to n-alkanes, it is difficult to represent all isomers' ignition characteristics using a single CS-component kinetics based on a single index (e.g. octane/cetane numbers), especially at low 
temperatures. It is because, although their indices are similar, the NTC behavior can substantially vary depending on their chemical structures. In the following section, the extension to the ReAd model to model iso-alkanes with an additional base-CS component and how iso-alkanes are classified is explained.

\subsection{Base-CS component for iso-Alkanes}

iso-Alkanes can be classified into lightly branched ( $\leq 2$ methyl branches) and highly branched (>2 methyl branches) in order to better represent their low-temperature ignition characteristic. The simplest branched alkanes are 2-methyl alkanes. According to Sarathy et al. [43], the role of the methyl branch in 2-methyl alkanes is more pronounced in smaller alkanes and reactivity does not change noticeably between the normal and 2methyl alkane isomer when the carbon chain reaches a critical length. Hence, it is more important to compare the reactivity of the normal and 2-methyl alkane isomers for $\mathrm{C}<10$ alkanes.

Table 5-1: Mono-methylated alkanes

\begin{tabular}{|c|c|c|}
\hline $\begin{array}{c}\text { Number of } \\
\text { carbons }\end{array}$ & $\begin{array}{c}\text { Number of } \\
\text { isomers }\end{array}$ & Short name of the isomers \\
\hline 4 & 1 & 2-methylpropane \\
\hline 5 & 1 & 2-methylbutane \\
\hline 6 & 2 & 2-methylpentane, 3-methylpentane \\
\hline 7 & 2 & 2-methylhexane, 3-methylhexane \\
\hline 8 & 3 & 2-methylheptane, 3-methylheptane, 4-methylheptane \\
\hline 9 & 3 & 2-methyloctane, 3-methyloctane, 4-methyloctane \\
\hline
\end{tabular}

Table 5-1 shows the number of different isomers with one methyl branch which can exist for alkanes with smaller than 9 carbons. The species in bold in Table 5-1 are iso-alkanes that have comprehensive mechanisms and measured IDTs over a wide range of temperatures available in the literature.

Figure 5-2 shows the IDTs curve of normal and 2-methyl branched alkane isomers along with the IDTs curve of a n-alkane with one fewer carbon. Simulations were performed for the reference condition of $\Phi=1.0$ and $\mathrm{P}_{\text {ini }}=40 \mathrm{bar}$. It can be seen that the IDTs of 2methyl alkanes are very close to those of the normal alkane with one fewer carbon. This ignition characteristic indicates that 2-methyl alkanes can be grouped with n-alkanes in the ReAd model and their reactivity can be represented by their RRIs as in the case of nalkanes. Additionally, other mono-methylated alkanes have similar ignition 
characteristics in the low to intermediate temperature range including the NTC region and their IDTs can be well correlated to their cetane numbers [43, 46]. A similar conclusion for 3-methylheptane and 2-methylheptane was reported by Wang et al. [47].

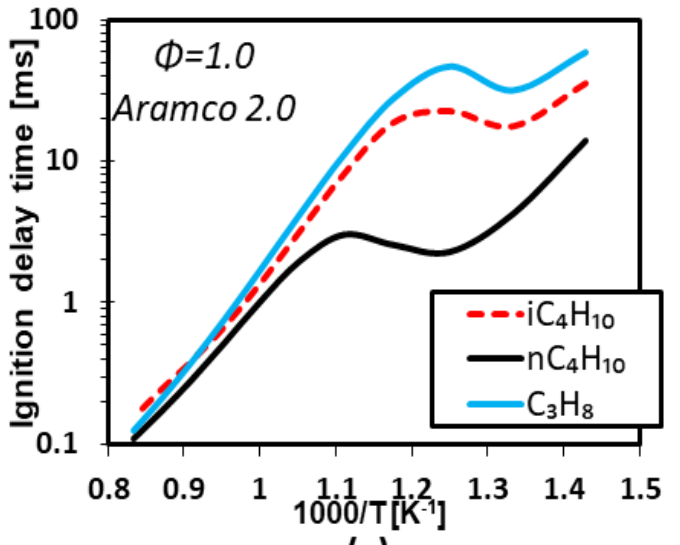

(a)

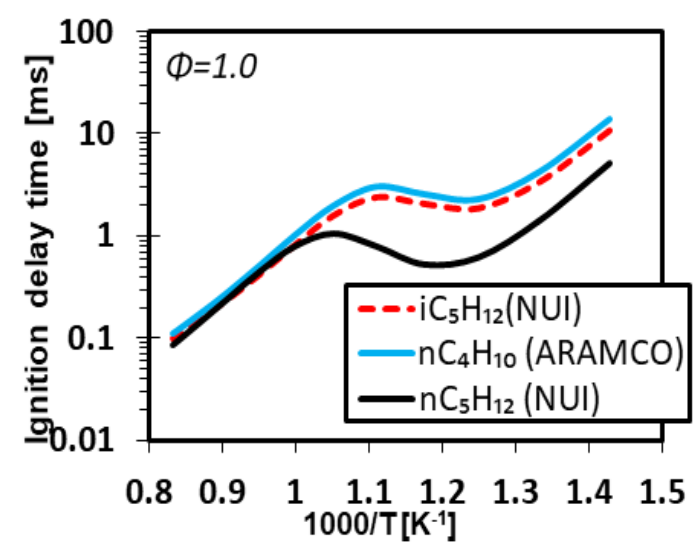

(b)

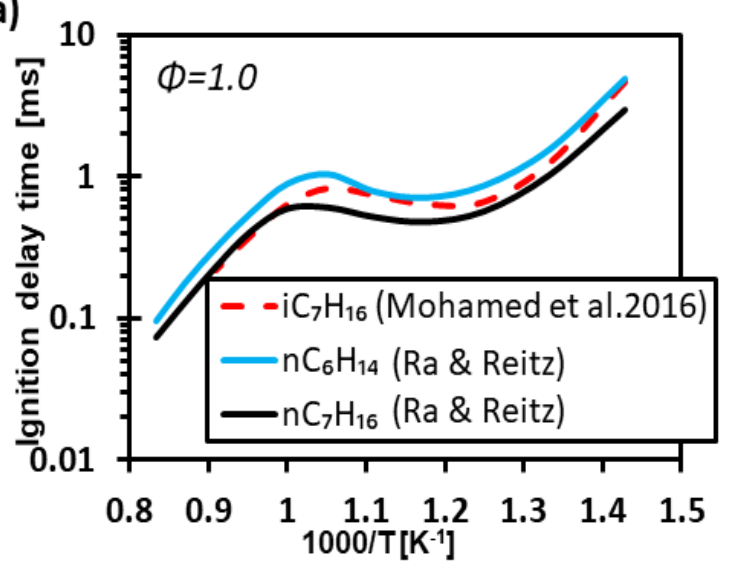

(c)

Figure 5-2: Simulated IDTs of 2-methylalkanes based on well-validated mechanism available. Simulated based on (a) ARAMCO 2.0 mechanism [48], (b) NUI Galway mechanism for pentane isomers [49] and n-butane from ARAMCO 2.0, (c) Mohamad et al.[50] and $\mathrm{Ra}$ and Reitz [26] mechanism

di-Methylated alkanes are not included in the surrogate fuel database as limited fundamental combustion studies are available for them likely due to high fuel cost for large-scale combustion experiments [51]. Additionally, the recent studies on dimethylated butane or di-methylated pentane show that the location of methyl branches can change the ignition characteristic in the low and intermediate temperature region likely due to different cyclic transition states that might not happen based on the location of methyl branches [52, 53].

For highly branched alkanes, iso-alkanes with the tertiary-butyl structure are considered in the study since that chemical structure is seen in some popular fuel components such as iso-octane and iso-cetane. 


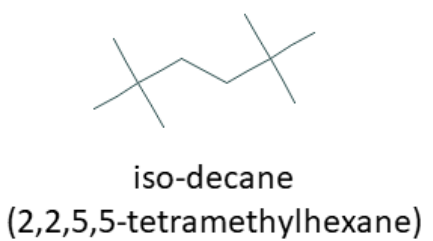

(2,2,5,5-tetramethylhexane)

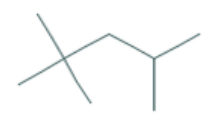

iso-octane

(2,2,4-trimethylpentane)

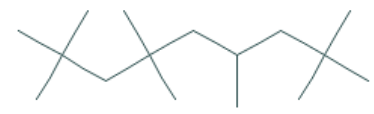

iso-cetane

$(2,2,4,4,6,8,8$-heptamethylnonae)

Figure 5-3: Molecular structure of highly-branched alkanes used in this study

Three highly branched alkanes shown in Figure 5-3 are considered in the fuel database. Note that the detailed reaction mechanisms of heavy alkanes are rarely available and experimental measurement of IDTs at low temperatures is quite challenging due to their low volatility (e.g., iso-cetane's vapor pressure is $130 \mathrm{~Pa} @ 20^{\circ} \mathrm{C}$ ).

Interestingly, however, the highly branched alkanes such as iso-decane and iso-cetane tend to have similar ignition characteristics to those of iso-octane due to their similar molecular structures. Iso-octane was chosen as the base-CS component for the highly branched alkanes. Following the method used for $\mathrm{n}$-heptane, three control reactions were selected, and their pre-exponential factors were adjusted to alter the IDT of the iso-octane mechanism. The selected control reactions are:

$$
\begin{aligned}
i C_{8} \mathrm{H}_{18}+\mathrm{OH} & \leftrightarrow i C_{8} \mathrm{H}_{17}+\mathrm{H}_{2} \mathrm{O} \\
i \mathrm{C}_{8} \mathrm{H}_{17} \mathrm{O}_{2} & \leftrightarrow i C_{8} \mathrm{H}_{16} \mathrm{OOH} \\
i \mathrm{C}_{8} \mathrm{H}_{18}+\mathrm{O}_{2} & \leftrightarrow i C_{8} \mathrm{H}_{17}+\mathrm{HO}_{2}
\end{aligned}
$$

The IDT curves of the control reactions are shown in Figure 5-4. C-5 and C-7 control reactions are hydrogen atom abstraction reactions, and C-6 control reaction is an isomerization reaction. C-5 and C-6 control reactions affect the IDTs of iso-octane at low to intermediate temperatures $(\mathrm{T}<1000 \mathrm{~K})$ and $\mathrm{C}-7$ control reaction affects the hightemperature region. 


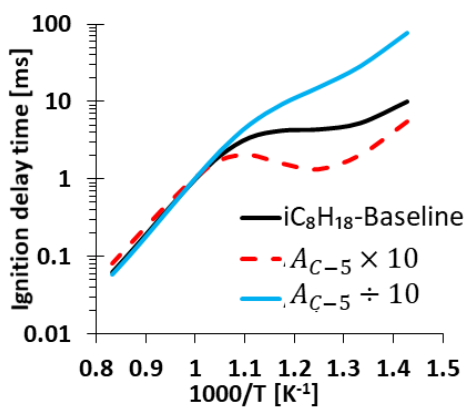

(a)

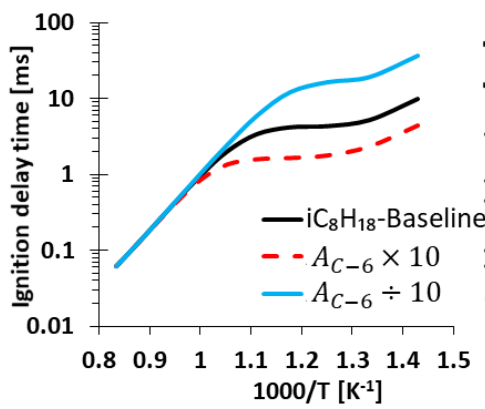

(b)

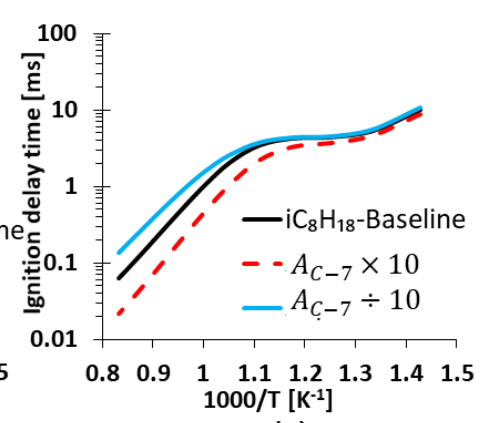

(c)

Figure 5-4: Sensitivity of IDT curve of iso-octane mechanism (a) reaction $\mathrm{iC}_{8} \mathrm{H}_{18}+\mathrm{OH}=\mathrm{iC}_{8} \mathrm{H}_{17}+\mathrm{H}_{2} \mathrm{O}$, (b) reaction $\mathrm{iC}_{8} \mathrm{H}_{17} \mathrm{O}_{2}=\mathrm{iC}_{8} \mathrm{H}_{16} \mathrm{OOH}$, (c) reaction $\mathrm{iC}_{8} \mathrm{H}_{18}+\mathrm{O}_{2}=\mathrm{iC}_{8} \mathrm{H}_{17}+\mathrm{HO}_{2}$

Iso-cetane and iso-decane (2,2,5,5-tetramethylhexane) are selected as the reference fuels. The reported cetane numbers of iso-cetane, iso-octane and iso-decane $(2,2,5,5$ tetramethylhexane) are 15.0, 13.5, and 12.0, respectively [37] that are in great agreement with obtained RRI of these iso-alkanes fuels while the two constants of the RRI correlation are $a=20$ and $b=7$ [26]. The RRI of these reference fuels based on their reaction mechanism is $15.0,13.15$ and 11.68 , respectively. The effect of equivalence ratio is also considered in the formulation of adjustment factor for highly branched alkanes. Similar to n-alkanes in order to improve the accuracy of the correlations it is divided to 2 regions of mixture reactivity. Refer to the method explained in detail in Section.4.4. The correlations of adjustment factors for the iso-octane mechanism are shown in Table 5-2. 
Table 5-2: Correlations of adjustment factor, $\mathrm{S}_{\mathrm{f}}$, for the control reactions C-5, C-6, and C7

\begin{tabular}{|c|c|c|}
\hline $\begin{array}{l}\text { Mixture } \\
\text { reactivity }\end{array}$ & Adjustment amount & \\
\hline \multirow{3}{*}{$\begin{array}{l}\text { higher than } \\
\text { iso-octane }\end{array}$} & $S_{f}(C-5)=a_{51} R R I_{m, 2}+b_{51} ; a_{51}=5.428, \quad b_{51}=-62.403$ & $(5-1)$ \\
\hline & $S_{f}(C-6)=a_{61} R R I_{m, 2}+b_{61} ; a_{61}=-0.484, b_{61}=6.659$ & $(5-2)$ \\
\hline & $S_{f}(C-7)=a_{71} R R I_{m, 2}+b_{71} ; a_{71}=0.034, \quad b_{71}=0.604$ & $(5-3)$ \\
\hline \multirow{2}{*}{$\begin{array}{l}\text { Higher } \\
\text { than iso- } \\
\text { decane }\end{array}$} & $S_{f}(C-5)=c_{51} R R I_{m, 2}+d_{51} ; \quad c_{51}=16.792, \quad d_{51}=-211.8$ & $(5-4)$ \\
\hline & $\begin{array}{l}S_{f}(C-7)=c_{71} R R I_{m, 2}+d_{71} ; \quad c_{71}=1.327, \quad d_{71}=- \\
16.406\end{array}$ & $(5-5)$ \\
\hline \multirow{2}{*}{\multicolumn{2}{|c|}{$S_{f}(C-6)=S_{f}(c-6) \cdot\left(a_{6} \Phi^{-2}+b_{6}\right)$}} & $(5-6)$ \\
\hline & & \\
\hline
\end{tabular}

\subsection{Base-CS component for aromatic hydrocarbons}

The model is extended further to represent the chemical kinetics of aromatic hydrocarbons. Aromatics with the benzene-ring structure can be classified as monocyclic or polycyclic-also known as MAH or PAH. The MAHs that are available in the fuel database are alkyl aromatic hydrocarbons as they are mainly studied in combustion chemistry. The PAHs available in the fuel database are 7 components including Indene, Tetralin, Naphthalene, Acenaphthalene, Acenaphthene, Phenanthrene, and Pyrene.

The reactivity of alkyl aromatic hydrocarbons is substantially different from normal and iso-alkanes. Typically aromatics components inhabit the oxidation of more reactive alkane components [54], when reacting in a co-oxidation environment. Additionally, as mentioned above in the selection of PS components, the fidelity of the surrogate fuel model also depends on its agreement with the $\mathrm{C} / \mathrm{H}$ ratio of the target fuel. Due to their high carbon to hydrogen ratio, alkyl aromatics can complement the alkanes surrogate models in the representation of $\mathrm{C} / \mathrm{H}$ ratio of the target fuels.

\subsubsection{Method I}

Toluene as the simplest alkyl aromatics studied in many chemical kinetics studies [5557]. Initiation of toluene oxidation is more likely to occur from $\mathrm{H}$-atom abstraction of the 
methyl group of toluene than $\mathrm{H}$-atoms bonded to the benzene ring that have high bond dissociation energies. It is also expected other alkyl aromatics follows the similar oxidation pathways. Hence toluene oxidation reactions can be used as a sub-model for oxidation of other heavier alkyl aromatics $[56,58]$.

Several detailed oxidation kinetics studies and experimental measurements show that, as the length of the alkyl chain of n-alkyl benzenes increases, the IDTs decrease and a similar but distinctive NTC behavior can be seen for n-alkyl benzenes with an alkyl chain of 4 carbons or longer [58]. On the contrary, alkylbenzenes with shorter alkyl chains than 4 carbons show a similar low-temperature ignition characteristic to that of toluene [59].

As it is shown in Figure 5-5 alkyl aromatic hydrocarbons in fuel database are classified to low-reactivity aromatics and high-reactivity aromatics to better represent their ignition characteristic with a fewer base-CS components. Toluene is selected as the third baseCS component to represent the ignition characteristic of low-reactivity aromatic hydrocarbons and high-reactivity aromatics that show distinctive NTC behavior are grouped with n-alkanes and their reactivity can be represented by their RRIs in a mixture.

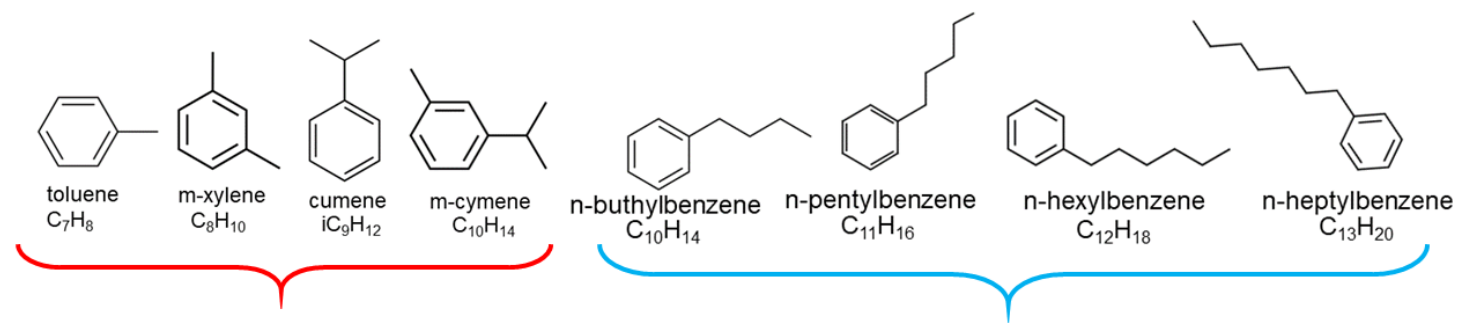

Figure 5-5: Classification of alkyl aromatic hydrocarbons in fuel database to lowreactivity aromatics -red left group, and high-reactivity aromatics -blue right group

Following the method used for the first base-CS component and explained in Section.4.4, a control reaction was selected and its pre-exponential factor was adjusted to alter the IDTs of the toluene mechanism. The selected control reaction is:

$$
\text { Benzyl }+\mathrm{O} 2 \leftrightarrow \mathrm{C} 6 \mathrm{H} 5+\mathrm{CH} 2 \mathrm{O}+\mathrm{O}
$$

The Control reaction C-8 affects IDTs at both low and high temperatures (See Figure 5-6). $\mathrm{m}$-Xylene, cumene (isopropyl-benzene) and m-cymene are selected as the reference fuels to calculate the amount of the adjustment in the ReAd model based on toluene as the base-CS component. The two constants of the RRI correlation are selected as $a=25$ and $b=0$ for low-reactivity aromatics [26]. 


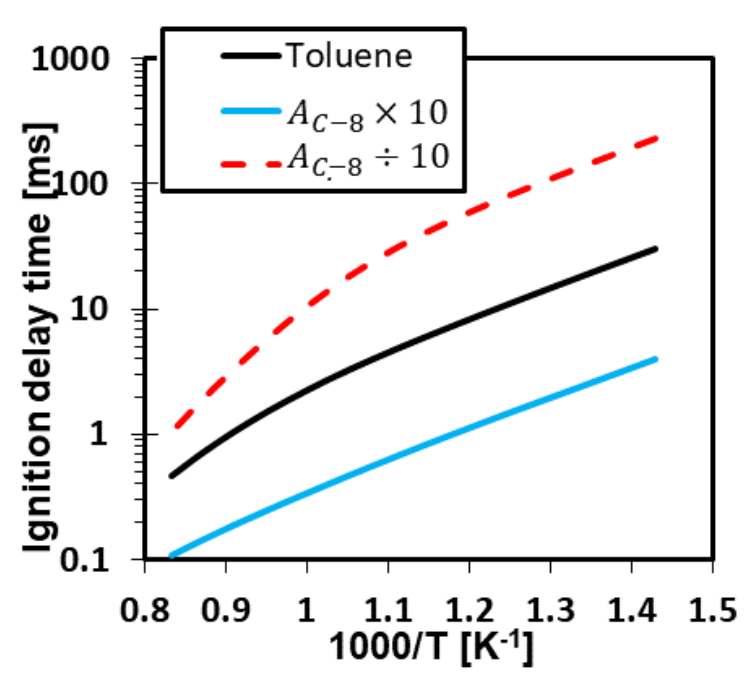

Figure 5-6: Sensitivity of IDT curve of toluene mechanism on reaction C-8, Benzyl $+\mathrm{O} 2 \leftrightarrow \mathrm{C} 6 \mathrm{H} 5+\mathrm{CH} 2 \mathrm{O}+\mathrm{O}$

The correlation of adjustment factors for the toluene mechanism is shown in Eq.(5-7):

$$
S_{f}(C-8)=a_{81} R R I_{m, 3}+b_{81} ; a_{81}=0.651, \quad b_{81}=-0.855
$$

\subsubsection{Method II}

Another effective approach instead of adjustment of pre-exponential factor of toluene mechanism to capture the reactivity of similar low-reactivity aromatics is genericreaction method suggested by $\mathrm{Ra}$ and Reitz [26]. The advantage of this method for lowreactivity aromatics including PAHs is that it can model the ignition characteristic of those components by adding a few species and reactions to the reduced mechanism of the base-CS component. For example, the ignition characteristic of n-propylbenzene can be modeled by adding 1 more species and 21 generic reaction steps to the reduced mechanism of toluene. The generic reaction steps that can be used for n-alkylbenzenes is shown in Table 5-3 as an example. The time-saving advantage of applying the reactivity adjustment of the toluene mechanism to model the ignition characteristic of aromatics is not remarkable compared to addition of the generic reaction steps and the latter method is used in this work for aromatic hydrocarbons. 
Table 5-3: Generic reaction steps used to model the oxidation kinetics of n-Alkylbenzene

$$
\begin{aligned}
& \text { n-Alkylbenzene }+\mathrm{H}=\text { Toluene/Benzene }+\dot{R} \text { (of alkenes) } \\
& \text { n-Alkylbenzene }+\mathrm{H}=\text { Benzyl/Phenyl }+ \text { Olefin }(\mathrm{s})+\mathrm{H}_{2} \\
& \text { n-Alkylbenzene }+\mathrm{OH}=\text { Toluene/Benzene }+\dot{R} \text { (of alkenes) }+\mathrm{CH}_{2} \mathrm{O} \\
& \text { n-Alkylbenzene }+\mathrm{OH}=\text { Benzyl/Phenyl }+ \text { Olefin }(\mathrm{s})+\mathrm{H}_{2} \mathrm{O} \\
& \text { n-Alkylbenzene } \left.+\mathrm{HO}_{2}=\text { Toluene/Benzene }+\dot{R} \text { (of alkenes }\right)+\mathrm{HCO}+\mathrm{OH} \\
& \text { n-Alkylbenzene }+\mathrm{HO}_{2}=\text { Benzyl/Phenyl }+ \text { Olefin }(\mathrm{s}) \\
& \text { n-Alkylbenzene }+\mathrm{O}=\text { Toluene/Benzene }+\dot{R}(\text { of alkenes })+\mathrm{HCO} \\
& \text { n-Alkylbenzene }+\mathrm{O}=\text { Benzyl/Phenyl }+ \text { Olefin }(\mathrm{s}) \\
& \text { n-Alkylbenzene } \left.+\mathrm{O}_{2}=\text { Toluene/Benzene }+\dot{R} \text { (of alkenes }\right)+\mathrm{HCO}+\mathrm{O} \\
& \text { n-Alkylbenzene }+\mathrm{O}_{2}=\text { Benzyl/Phenyl }+ \text { Olefin }(\mathrm{s}) \\
& \text { n-Alkylbenzene } \quad=\text { Phenyl }+\dot{R} \text { (of alkenes) }
\end{aligned}
$$




\section{Validation of adjustment factor correlations}

As mentioned in Section.4, the IDTs of the reference fuels in a constant volume reactor are used to formulate the adjustment factor correlations in Table 4-1, Table 5-2 and Eq.(5-7). It is important to back-test the performance of the ReAd model based on the correlations for constant volume simulation the reference fuels. The IDT curves predicted by the present ReAd model for the reference fuels of n-alkanes, iso-alkanes and aromatics families were compared with those obtained using their own reaction kinetics mechanisms [26] in Figure 6-1, Figure 6-2 and Figure 6-3, respectively.

Figure 6-1 shows the results of IDTs of stoichiometric fuel/air mixtures for an initial pressure of 40 bar and initial temperatures of $700-1300 \mathrm{~K}$ at a constant volume simulation. It can be seen that the IDTs of these reference fuels from n-alkanes are well captured by the reactivity adjustment formula obtained from Table 4-1 for n-heptane reaction mechanism. For example, the results shown with the ReAd label for n-dodecane in Figure 6-1-(d) use Eq.(4-12) and Eq.(4-13) to obtain the reactivity adjustment amount, while Eq.(4-17) and Eq.(4-18) were used for n-pentane simulation. This back-testing method validates the performance of the correlation shown in Table 4-1.

Additionally, the following formula is suggested to calculate the error of predicted IDT at temperature $\mathrm{T}$ between the ReAd model- that use the adjustment factor correlation- and PSGCR method-that use the reference fuels' their own reaction mechanism.

$$
\operatorname{Error}_{T}=\left|\frac{\log \left(\tau_{R e A d}^{T}\right)-\log \left(\tau_{P S G C R}^{T}\right)}{\log \tau_{C S}^{700}}\right|
$$

In above equation, $\tau_{R e A d}^{T}$ and $\tau_{P S G C R}^{T}$ are the IDT in millisecond (ms) at initial temperature, T, using the ReAd model and the PSGCR method, respectively. The $\tau_{C S}^{700}$ in the denominator of Eq.(6-1) is IDT of selected CS for the ReAd model at initial temperature of $700 \mathrm{~K}$. The mean error is measured based on the average of the errors calculated from Eq.(6-1) in temperature range of $700 \mathrm{~K}$ to $1300 \mathrm{~K}$ with increment of $50 \mathrm{~K}$.

To find the optimum amount that the control reactions should be altered to have the lowest mean error, a method similar to the gradient optimization method [60] to find a minimum of a function is used.

Initially, the adjustment factor, $S_{f}$, of the control reactions are slightly $(+/-0.5)$ changed and the average error is calculated in two neighboring points. If the average error is the smaller in either of the neighboring points, the corresponding $S_{f}$ to the smaller error is chosen as the new $S_{f}$. This process is continued until to reach a point that the average error in both directions (i.e., $\left.S_{f}+/-0.5\right)$ is larger than the previous value. Then, the search will continue with a smaller (+/- 0.1$)$ change in $S_{f}$ until to find another minimal average error. 

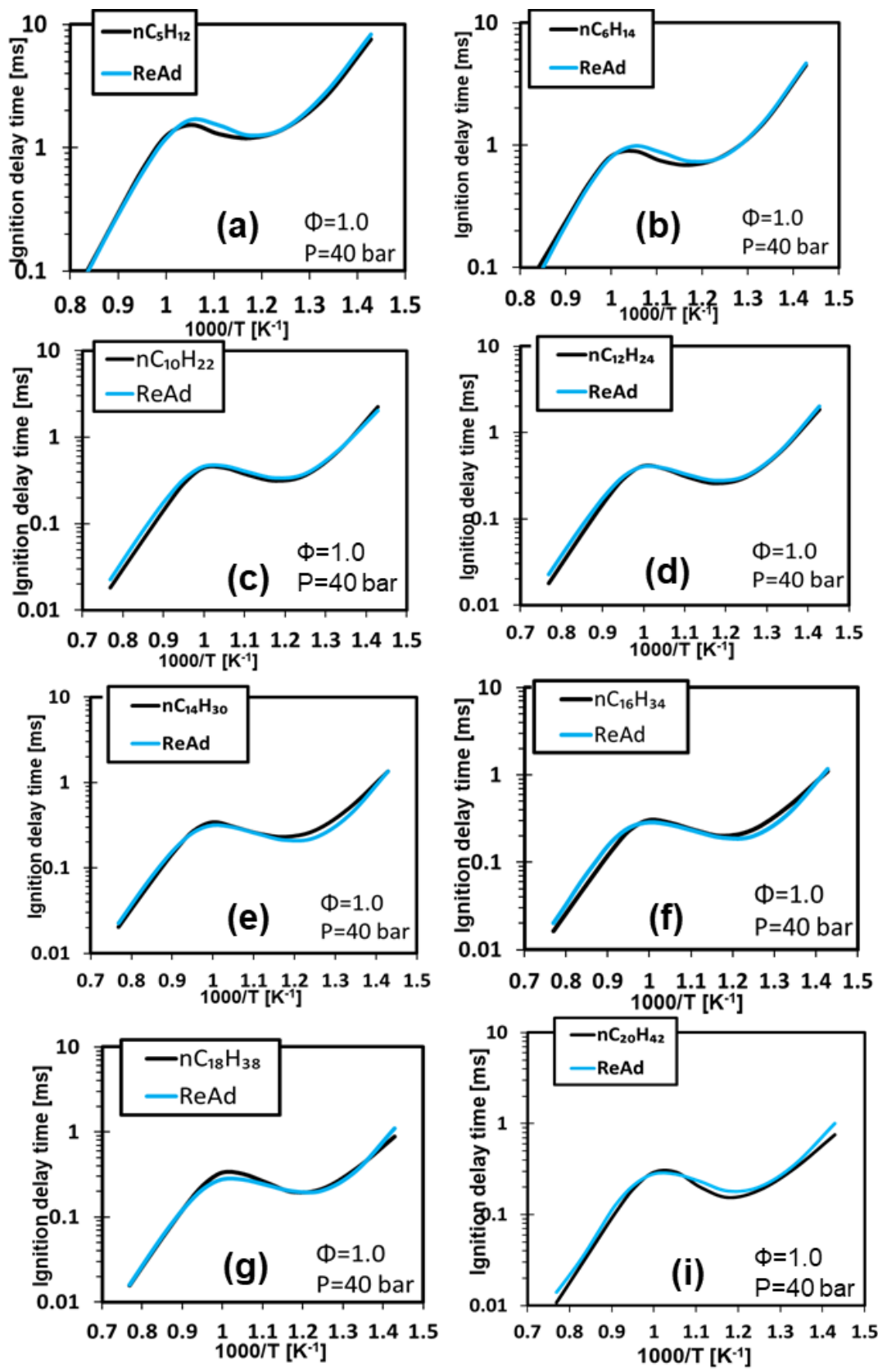

Figure 6-1: Comparison of simulated IDTs obtained by the ReAd model and based on the reduced mechanism for (a) n-pentane, (b)n-hexane, (c)n-decane, (d)n-dodecane, (e) n-tetradecane, (f) n-cetane, (g) n-octadecane, (i) n-icosane 
Figure 6-2 shows the results of IDTs of the reference fuels from iso-alkane family. It is shown that the IDTs of these reference fuels are well captured by reactivity adjustment formula obtained from Table 5-2 for iso-octane reaction mechanism.
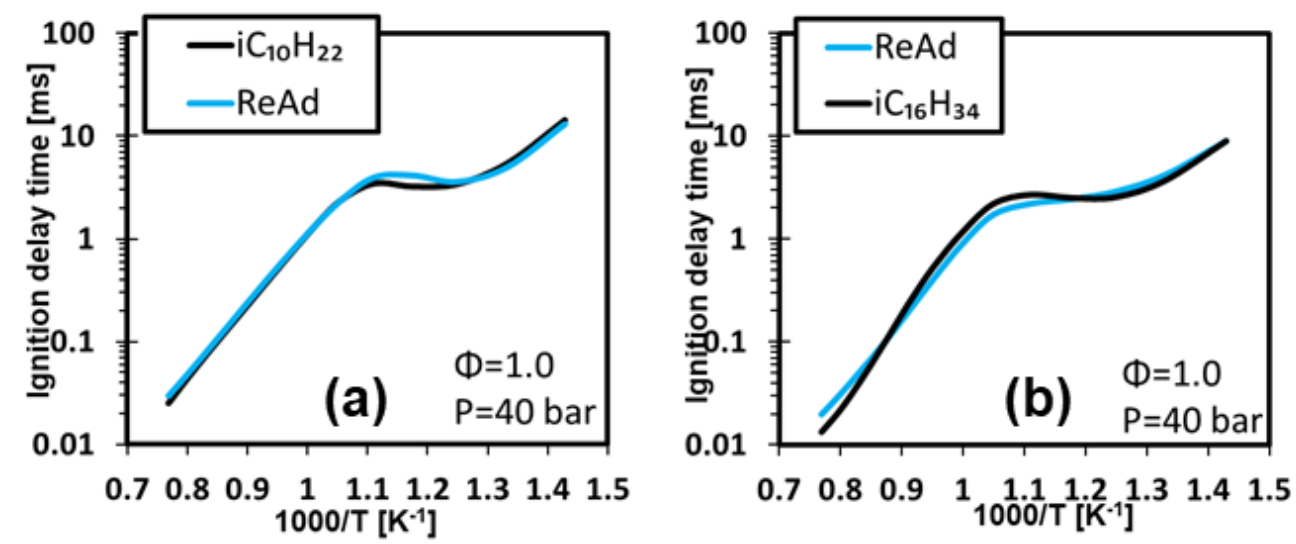

Figure 6-2: Comparison of simulated IDTs obtained by the ReAd model and based on the reduced mechanism for the reference fuels in iso-alkanes family (a) iso-octane (trimethylpentane), (b) iso-octane

The results of IDTs of the reference fuels from aromatics family are shown in Figure 6-3. As explained in Section.5.2, the IDTs of these reference fuels is obtained by reactivity adjustment formula in Eq.(5-7). Note that simulations are performed for stoichiometric fuel/air mixtures at a constant volume reactor. Again, these back-testing simulations validates the formula shown in Eq.(5-7). 

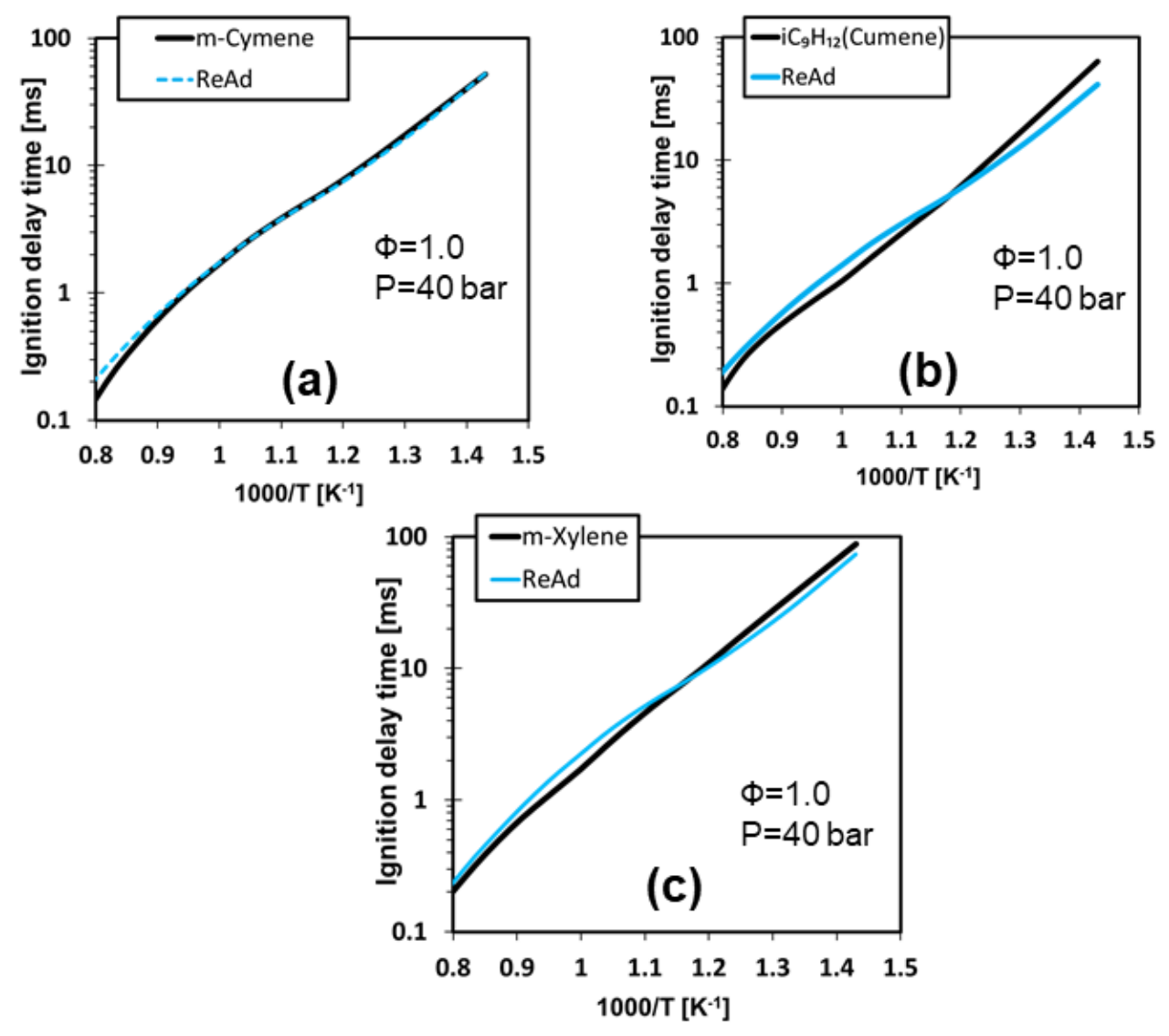

Figure 6-3: Comparison of simulated IDTs obtained by the ReAd model and based on the reduced mechanism of reference fuels for (a) m-cymene, (b) iso-propylbenzene (cumene), (c) m-xylene 


\section{Results and discussion}

Using the developed model, various multi-component fuel models are tested in various combustion modes, and their results are presented in this section. The performance of the ReAd model is compared with that of the PSGCR model and GCR model in term of the prediction accuracy and computational time. Note that in the PSGCR model, the number of CS components is the same as the number of PS component, and thus the oxidation kinetics of PS components is described by their own chemical reaction mechanisms. This indicates that the best accuracy of the ReAd model is achieved when the ReAd model simulation results capture those predicted by the PSGCR model results. It should also be noted that, in the following simulations, both the GCR and ReAd models use the same set of CS components and chemical reaction mechanisms and thus the comparison between the two models demonstrates the role of the ReAd model in improvement of prediction accuracy.

\subsection{Ignition of homogeneous mixtures in a constant volume reactor}

Ignition of a two-component fuel was simulated to demonstrate the performance of the re-distribution scheme of the ReAd model. A blend (50/50 by mass) of $n$-heptane and $n$ decane was tested for an initial pressure of $40 \mathrm{bar}$ and an initial temperature of $850 \mathrm{~K}$ and the profiles of temperatures and fuel component mass fractions are shown in Figure 7-1. Three models are compared in the figure; i) the PSGCR approach, ii) the GCR approach, and iii) the ReAd model. Note that both components are assigned to n-heptane (the CS component) kinetics in both the GCR and the ReAd models, but the reactivity of the nheptane mechanism is adjusted to represent the average reactivity of the blend fuel and the re-distribution scheme is activated in the ReAd model.

The GCR method assumes no reactivity difference of the grouped fuel components. Therefore, the predicted IDTs by the GCR method is shown to be longer than those predicted by the PSGCR model, as can be seen from the main ignition timings (second temperature jump in the temperature profiles) in Figure 7-1. It is also seen that both the cool flame and the main ignition timings are in good agreement with those by the ReAd model although the main IDT is slightly over-predicted. This confirms that the average reactivity of the mixture is correctly captured by the ReAd model.

The profiles of the two components' mass are identical in the GCR method, since their initial composition of 50\%/50\% mass in the mixture would not change because no distinction of component reactivity is considered in distributing the updated amounts of the chemical surrogate component (n-heptane) after chemistry calculation back to the two physical surrogate components (n-decane and n-heptane). On the contrary, the mass profiles predicted by the PSGCR method reveal that the consumption (oxidation) rate of the higher-reactive component (n-decane) is greater than that of the lower reactivity component (n-heptane). 
Fuel components' consumption profiles could be well captured by the redistribution feature of the ReAd model, although the consumption rate of the lower-reactivity fuel was slightly under-predicted compared to that by the PSGCR method. The under-

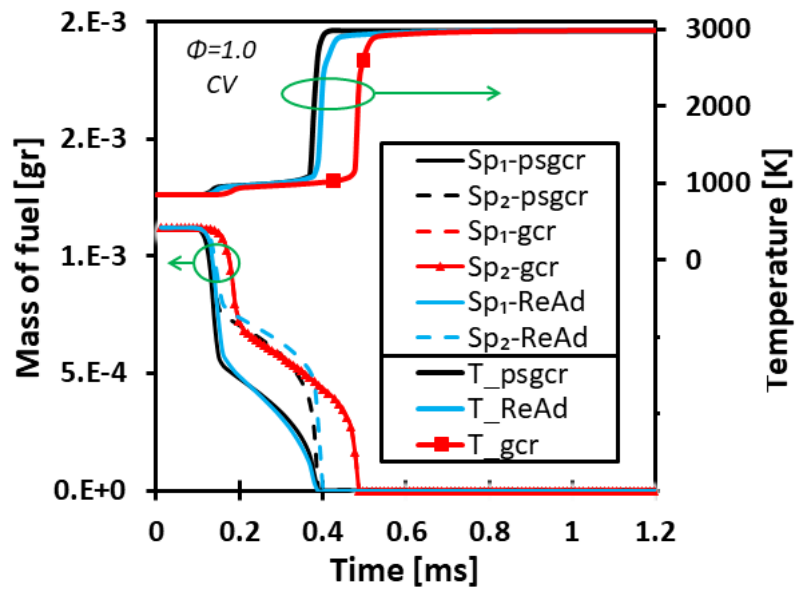

Figure 7-1: Mass and temperature variation of 2-component fuel $\left(\mathrm{Sp}_{1}\right.$ is $\mathrm{n}$-decane and $\mathrm{Sp}_{2}$ is $\mathrm{n}$-heptane). Simulated in a CV reactor with an initial pressure and temperature of 40 bar and $850 \mathrm{~K}$, respectively.

prediction is attributed to the fact that the ReAd model cannot take into account the effect of reaction interaction between the components (the co-oxidation effect), while it is modelled by the PSGCR method.

\section{2 $\mathrm{HCCl}$ engine combustion}

The present model was also validated against experiments of homogeneous charge compression ignition combustion in a light-duty diesel engine with a compression ratio of 10.5 [61]. The fuel considered in the simulation is FACE\#1. The FACE\#1 is a fuel from a set of research fuels designed and developed in a joint project between the US Department of Energy and Coordinating Research Council [61]. The surrogate compositions proposed by Krishnasamy et al. [62] is used in the simulation. The PS and CS components and their compositions for the PSGCR, GCR and ReAd models are shown in Table 7-1. The 11-component surrogate model matches the fuel distillation profile as well as the specific gravity, lower heating value, hydrogen-to-carbon $(\mathrm{H} / \mathrm{C})$ ratio, and CN of FACE\#1 [62]. As it is mentioned in Section.1.3, in the PSGCR the PS components don't need to be grouped into chemical surrogate components because each PS component has its own CS component with reaction kinetics described in the mechanism. However, in GCR and ReAd method, cyclo-alkanes, high-reactivity aromatics and $\mathrm{n}$-alkanes are grouped and assigned to $\mathrm{n}$-heptane. iso-Alkanes are grouped into iso-octane and low-reactivity aromatics are grouped and assigned to toluene as can be seen in Table 7-1. Note that naphthalene and tetralin are assigned to toluene for 
kinetics calculation due to similar low-reactivity characteristic even though they are not used as reference fuels in formulation of Eq.(5-7).

Table 7-1: 11-component Surrogate FACE\#1 model

\begin{tabular}{|c|c|c|c|}
\hline $\begin{array}{l}\text { 11-Component } \\
\text { FACE\#1 PS Model }\end{array}$ & $\begin{array}{l}\text { Mass } \\
\text { fraction }\end{array}$ & $\begin{array}{l}\text { PSGCR, } \\
\text { CS model }\end{array}$ & $\begin{array}{l}\text { ReAd \& } \\
\text { GCR } \\
\text { CS model }\end{array}$ \\
\hline n-dodecane, $\mathrm{n}-\mathrm{C}_{12} \mathrm{H}_{26}(\mathrm{nA})$ & 0.162 & $\mathrm{n}-\mathrm{C}_{12} \mathrm{H}_{26}$ & \multirow{2}{*}{$\begin{array}{l}\text { n-heptane, } \\
\mathrm{nC}_{7} \mathrm{H}_{16}\end{array}$} \\
\hline n-octadecane, $n-\mathrm{C}_{18} \mathrm{H}_{38}(\mathrm{nA})$ & 0.101 & $\mathrm{n}-\mathrm{C}_{18} \mathrm{H}_{38}$ & \\
\hline $\begin{array}{l}\text { 2,2,3,3-tetramethylhexane, } \\
\mathrm{iC}_{10} \mathrm{H}_{22}(\mathrm{iA})\end{array}$ & 0.260 & $\mathrm{iC}_{10} \mathrm{H}_{22}$ & \multirow{2}{*}{$\begin{array}{l}\text { iso-octane, } \\
\mathrm{iC}_{8} \mathrm{H}_{18}\end{array}$} \\
\hline iso-cetane, $\mathrm{iC}_{16} \mathrm{H}_{34}(\mathrm{iA})$ & 0.100 & $\mathrm{iC}_{16} \mathrm{H}_{34}$ & \\
\hline cyclohexane, $\mathrm{C}_{6} \mathrm{H}_{12}(\mathrm{cA})$ & 0.030 & $\mathrm{C}_{6} \mathrm{H}_{12}$ & \multirow{2}{*}{$\begin{array}{l}\text { n-heptane, } \\
\mathrm{nC}_{7} \mathrm{H}_{16}\end{array}$} \\
\hline decalin, $\mathrm{C}_{10} \mathrm{H}_{18}(\mathrm{cA})$ & 0.120 & $\mathrm{C}_{10} \mathrm{H}_{18}$ & \\
\hline tetralin, $\mathrm{C}_{10} \mathrm{H}_{12}(\mathrm{mAH})$ & 0.008 & $\mathrm{C}_{10} \mathrm{H}_{12}$ & \multirow{3}{*}{ toluene } \\
\hline naphthalene, $\mathrm{C}_{10} \mathrm{H}_{8}(\mathrm{pAH})$ & 0.015 & $\mathrm{C}_{10} \mathrm{H}_{8}$ & \\
\hline m-cymene, $\mathrm{C}_{10} \mathrm{H}_{14}(\mathrm{mAH})$ & 0.152 & $\mathrm{C}_{10} \mathrm{H}_{14}$ & \\
\hline n-pentylbenzene, $\mathrm{C}_{11} \mathrm{H}_{16}(\mathrm{mAH})$ & 0.042 & $\mathrm{C}_{11} \mathrm{H}_{16}$ & \multirow{2}{*}{$\begin{array}{l}\text { n-heptane, } \\
\mathrm{nC}_{7} \mathrm{H}_{16}\end{array}$} \\
\hline n-heptylbenzene, $\mathrm{C}_{13} \mathrm{H}_{20}(\mathrm{mAH})$ & 0.010 & $\mathrm{C}_{13} \mathrm{H}_{20}$ & \\
\hline $\begin{array}{l}\text { nA: normal-alkanes | iA: iso-Alk } \\
\text { mAH: monocyclic Aromatic Hyd } \\
\text { pAH: polycyclic Aromatic Hydro }\end{array}$ & $\begin{array}{l}\text { hes } \mathrm{cA} \text { : } \\
\text { carbons } \\
\text { arbons }\end{array}$ & yclo-alkane & \\
\hline
\end{tabular}

The engine specification and operating conditions used in the simulation are listed in Table 7-2, and more details can be found in [62]. The boundary conditions of the engine were estimated based on the engine load and the relevant measured data available in the literature [63]. The trapped residual gases were estimated based on the in-cylinder gas pressure and estimated temperature at the exhaust valve closure (EVC) timing. The internal residual gases were added to the fresh fuel/air to specify the mixture composition at intake valve closure (IVC). 
Table 7-2: engine specification and operating condition used in the HCCI engine combustion simulation

\begin{tabular}{|l|l|}
\hline Bore x Stroke [mm x mm] & $97.0 \times 70.0$ \\
\hline Compression ratio & 10.5 \\
\hline Inlet Valve closing [o ATDC] & -142 \\
\hline Exhaust Valve opening [ ${ }^{\circ}$ ATDC] & 139 \\
\hline Engine Speed [rev/min] & 1800 \\
\hline Fuel rate [g/min] & 6.27 \\
\hline Equivalence ratio & 0.31 \\
\hline Intake manifold Pressure [bar] & 0.98 \\
\hline Intake manifold Temperature [ $\left.{ }^{\circ} \mathrm{K}\right]$ & 513 \\
\hline
\end{tabular}

To reduce computation time, a 2-D sector grid with a total of 1415 cells at the bottomdead-center (BDC) was used. The crevice volume was resolved as an elongated top land region connected to a trapezoidal region to represent the crevice groove volume. The crevice volume was optimally adjusted to match the effective compression ratio of the engine. Figure 7-2 shows the computational grid at the BDC. 


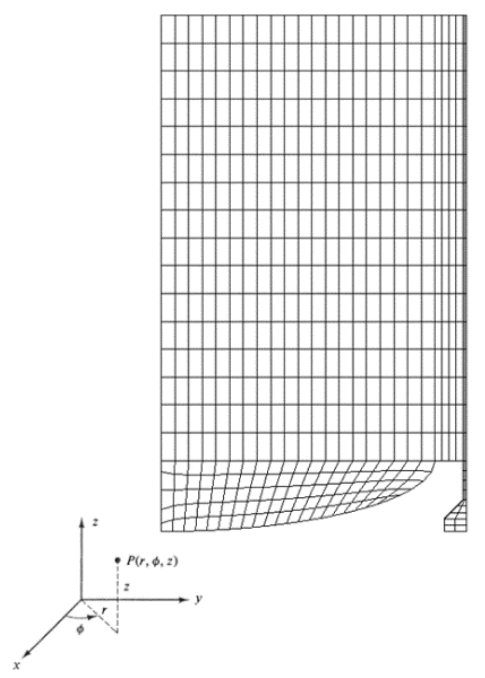

Figure 7-2: Computational grid used in the HCCI engine combustion simulation at $\mathrm{BDC}$

Figure 7-3-(a) shows a comparison of the pressure and heat release rate profiles between predictions by the PSGCR method and the experimental data. The results by the PSGCR model are used as the reference to compare with the results by the present ReAd model. The predictions are in good agreement with the measured data, although the predicted peak pressure is slightly higher than the measured values. It is seen in Figure 7-3-b that the pressure and heat release rate profiles predicted by the ReAd model are in good agreement with those of the PSGCR model, which indicates the ReAd model successfully predict the reactivity of the real multi-component fuel. The difference between the predictions by the ReAd model and the PSGCR model indicates the difference between the reactivity of the blend of fuels based on the chemical reaction mechanism and that of the model. On the contrary, the GCR model under-predict the reactivity of the mixture so that ignition is substantially retarded. This is expected because no reactivity adjustment is made in the GCR model in spite of the difference of average $\mathrm{CN}$ between the PS composition $(\mathrm{CN}=38.3)$ and that of the $\mathrm{CS}$ composition for the GCR model $(\mathrm{CN}=31.8)$. 


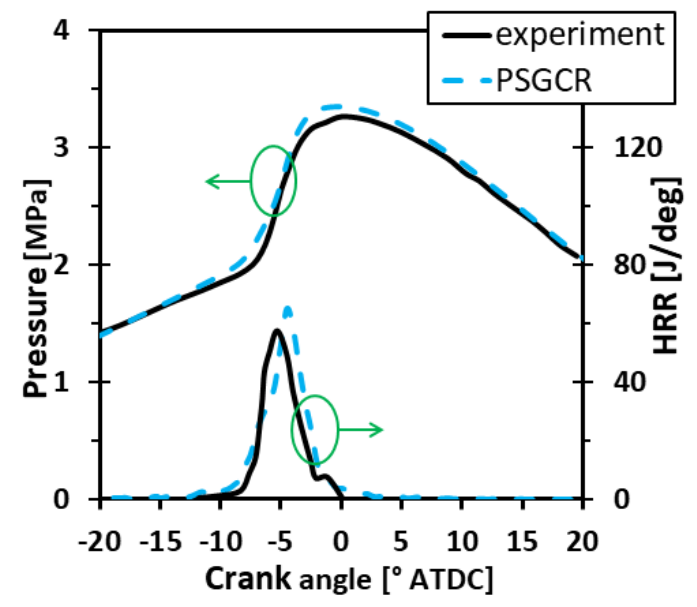

(a)

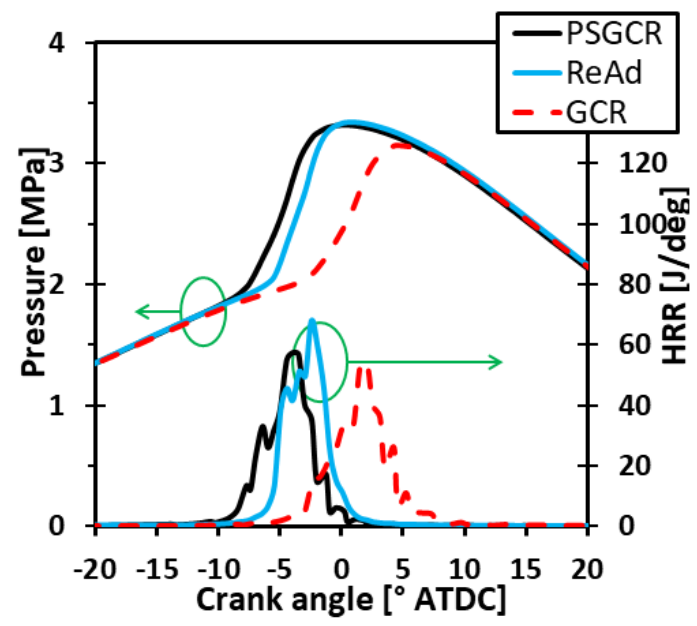

(b)

Figure 7-3: Comparison of (a) measured and predicted in-cylinder pressure and heat release rate (HRR), (b) predicted pressure and HRR profiles based 3 different combustion models.

The comparison of computation times with the three models is shown in Figure 7-4. The computation times are for simulations from IVC to exhaust valve closure (EVO) employing the Intel® Xeon X5650 processor. The same mechanism (143 species and 594 reactions) was used for both ReAd and GCR simulations. Note that the reaction mechanism of 3 CS components (n-heptane, iso-octane and toluene) has 132 species and 594 reactions. 11 PS components of FACE\#1 are added as nominal species in reaction mechanism, but they are not involved in the reaction mechanism. They are added because their thermodynamic properties such as specific heat, standard state enthalpy and entropies are obtained based on an input file (therm.dat) that is used in pre-processing of the chemistry solver. It can be seen that the ReAd model can save $79 \%$ of computation time compared to the PSGCR method that employs a larger mechanism (253 species and 1102 reactions). The simulations with ReAd model and GCR model are also show comparable computational time as both use the same reaction mechanism. However, the total computational time is slightly different $(\sim 1.49 \mathrm{~min})$ due to the difference in total chemical kinetics, local reactivity $\left(R R I_{m, j}\right)$, and adjustment factor calculations. 


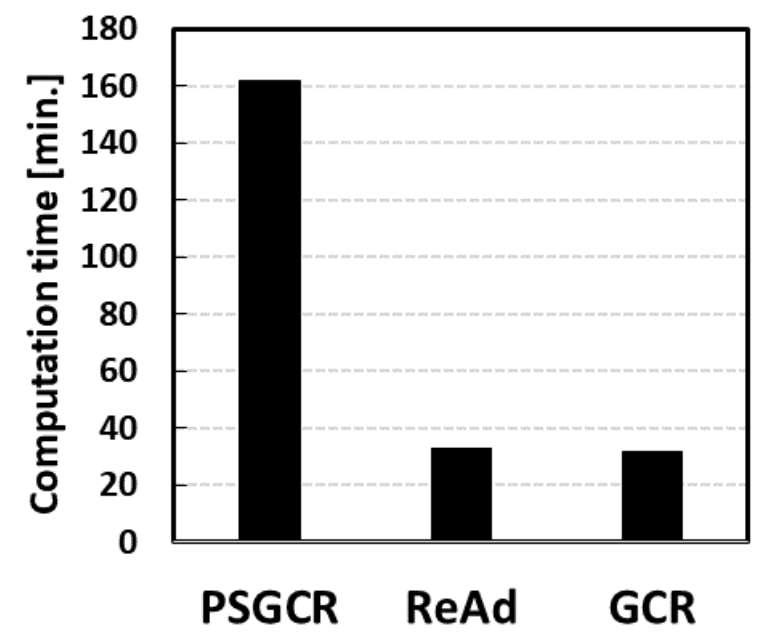

Figure 7-4: Total computation times for the HCCI engine simulation with different combustion models.

\section{3 $\mathrm{RCCl}$ engine combustion simulation}

The performance of the model is also validated against an RCCI engine experiment. The engine modeled is a 4-cylinder 1.9L Volkswagen diesel engine that is equipped with a turbocharged direct injection (DI) system and a EGR control system [64]. The specification of the engine is listed in Table 7-3.

The direct-injected fuel was delivered through a common rail system to Bosch CRDI injectors which were mounted on the center of the cylinders head. The injector has 6 nozzles with a diameter of $0.165 \mathrm{~mm}$ and a spray-included angle of 144 degrees. The intake manifold of the original engine was modified to allow port fuel injection (PFI) for the dual-fuel RCCI operation. 
Table 7-3: Specification of the 1.9L engine used in the RCCI engine simulation

\begin{tabular}{|l|l|}
\hline Bore (mm) & 79.5 \\
\hline Stroke $(\mathrm{mm})$ & 95.5 \\
\hline Connecting Rod Length (mm) & 14.4 \\
\hline \multirow{2}{*}{ Intake Valve Timing ( ${ }^{\circ}$ ATDC) } & Open -354 \\
\cline { 2 - 2 } & Close -169 \\
\hline \multirow{2}{*}{ Exhaust Valve Timing ( ${ }^{\circ}$ ATDC) } & Open 162 \\
\cline { 2 - 2 } & Close 351 \\
\hline
\end{tabular}

\subsubsection{Simulated operating condition}

In the RCCI operation mode, methane with a minimum purity of $99.5 \%$ is injected at 4 bar into the intake port when the intake valve is open. Ultra-Low Sulfur Diesel (ULSD) as the high reactive fuel is injected directly into the cylinder through the high-pressure common rail system at a constant pressure of 400 bar. The delay between the injection pulse command and the actual start of injection was $0.432 \mathrm{~ms}$ for an injection pressure of 400 bar and chamber pressures of 26 38 bar. Detailed engine operating conditions for model validation are given in Table 7-4. 
Table 7-4: Operating conditions of the RCCI engine combustion.

\begin{tabular}{|l|l|}
\hline & RCCI-Case1 \\
\hline Engine load (bar) & 4 \\
\hline Engine Speed (rev/min) & 1300 \\
\hline Natural gas flow rate (g/s) & 0.5 \\
\hline Air flow rate (kg/h) & 60.736 \\
\hline Diesel flow rate (g/s) & 0.071 \\
\hline \begin{tabular}{l} 
st pulse split ratio (\%) \\
\hline Injection timing ( $\left.{ }^{\circ} \mathrm{BTDC}\right)$
\end{tabular} & 100 -single \\
\hline Injection duration (ms) & 20 \\
\hline Injection pressure (bar) & 0.32 \\
\hline EGR (\%) & 400 \\
\hline
\end{tabular}

\subsubsection{Numerical modeling}

\subsubsection{Computational grid of 1.9L VW engine}

A full $360^{\circ}$ engine mesh was generated since the cylinder bowl is off-centered from the cylinder axis. The average cell dimensions at the top-dead-center (TDC) were 1.85 and $1.2 \mathrm{~mm}$ in the radial and vertical directions, respectively. As it can be seen in Figure 7-5(a) that the mesh is finer in the center region of the bowl to better resolve the sprays from the injector aligned to the axis of the bowl. The computational grid was generated with ICEM CFD software [65]. The crevice volume was resolved as an elongated top land region, which was adjusted to match the effective compression ratio of the engine. 


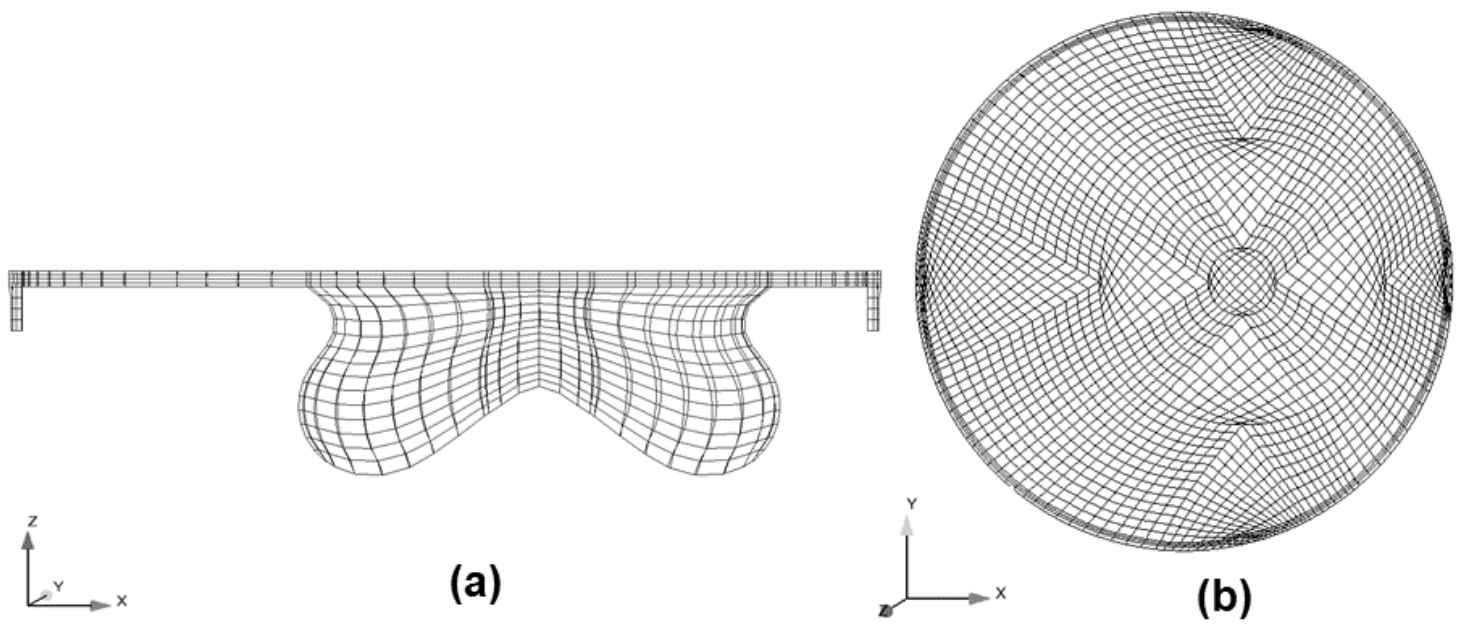

Figure 7-5: Computational grid for the 1.9L engine at TDC. (a) side mid-plane view,

(b) top plane view

\subsubsection{Fuel model}

The high reactive fuel in the RCCI operation is ULSD. The 19-component diesel model shown in Table 2-1 is used for the PS components.

For simulations with the ReAd and GCR models, the PS components in the chemical classes of n-alkanes, cyclo-alkanes, high-reactivity aromatics and olefins are assigned to n-heptane and the branched alkanes are assigned to iso-octane. The low-reactivity aromatic hydrocarbons are grouped and assigned to toluene. The chemistry of the low reactive fuel, methane, is modelled using the $\mathrm{CH}_{4}$ oxidation kinetics mechanism, which is a common sub-mechanism in the parent mechanisms.

\subsubsection{Evaluation of the mechanism for RCCl engine simulation}

Figure 7-6-(a) shows the IDTs of neat stoichiometric methane/air mixtures at an initial pressure of 40 bar. The experimental data of shock-tube test by Huang et al. [66] are shown with the prediction results. It is seen that the predicted IDTs are in goodagreement with the measured shock-tube data.

The IDTs for temperatures lower than $900 \mathrm{~K}$ are predicted to be longer than $10 \mathrm{~ms}$ which is equivalent to 90-degree CA in an IC engine operates at and engine speed of 1500 $\mathrm{rev} / \mathrm{min}$. These long IDTs are beyond the residence time available for combustion of methane in conventional IC engines. Hence ignition is driven by the combustion of a high-reactive fuel directly injected into the combustion chamber. 
Figure 7-6-(b) shows the predicted IDTs of stoichiometric mixtures of 19-component ULSD surrogate and methane blends along with neat diesel and methane cases. The IDTs of the 80/20 methane/diesel blend are significantly reduced from those of neat methane/air mixtures and with further increase of diesel portion to 50\%, the IDTs are predicted to decrease to $\sim 1 \mathrm{~ms}$ for mixture temperatures of compression gases $(800<\mathrm{T}<$ 1000 ) in typical diesel engines. This reduced IDT is short enough to drive the ignition of the local fuel/air mixtures while they stay at high temperatures near TDC.

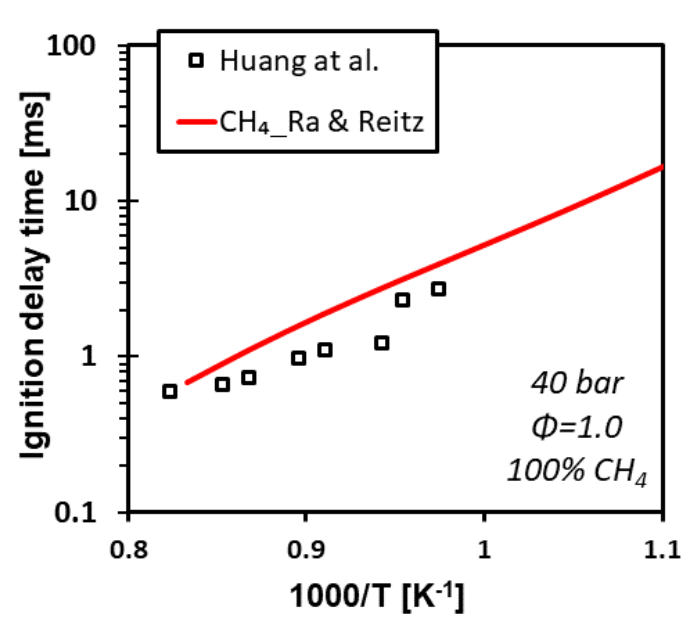

(a)

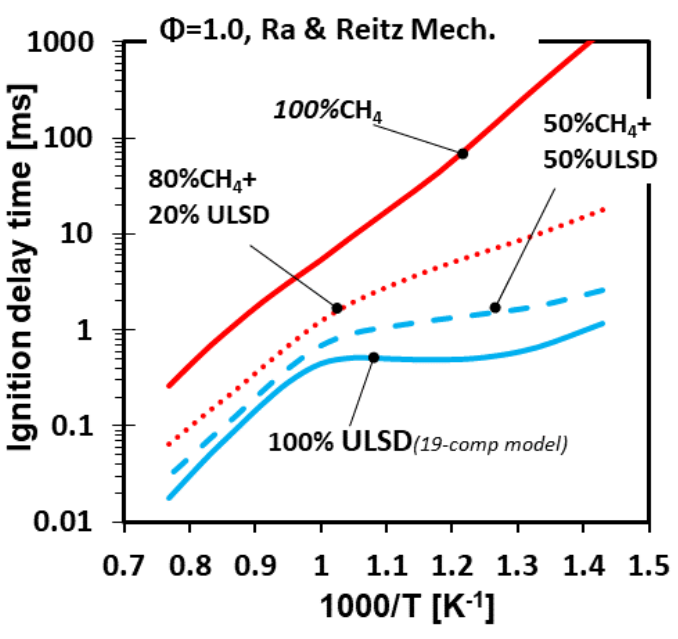

(b)

Figure 7-6: Comparison of IDTs of stoichiometric fuel-air mixtures. (a) neat methane; symbols- experimental data by Huang et al.[66],line- model prediction using Ra and Reitz. [26] mechanism, (b) $50 \%$ and $80 \%$ blends by mass of methane/ULSD surrogate, neat methane and neat ULSD.

\subsubsection{Simulation Setup and Results}

The operating conditions listed in Table 7-4 were simulated. The computations were performed from IVC to EVO. Homogenous methane/air mixture with internal residual gases of $5 \%$ by mass was assumed at IVC. The wall temperature boundary conditions were estimated to be 490,520 and $450 \mathrm{~K}$ for the head, piston and linear of the engine, respectively, based on engine load and the relevant measured data in the literature. As is shown in Figure 7-7-(a), the motoring pressure profile is well captured by using the boundary conditions. The predicted ignition timing and the pressure rise by the combustion of methane are seen to be in good agreement with the measured data, although the peak pressure and AHRR are slightly over-predicted. 


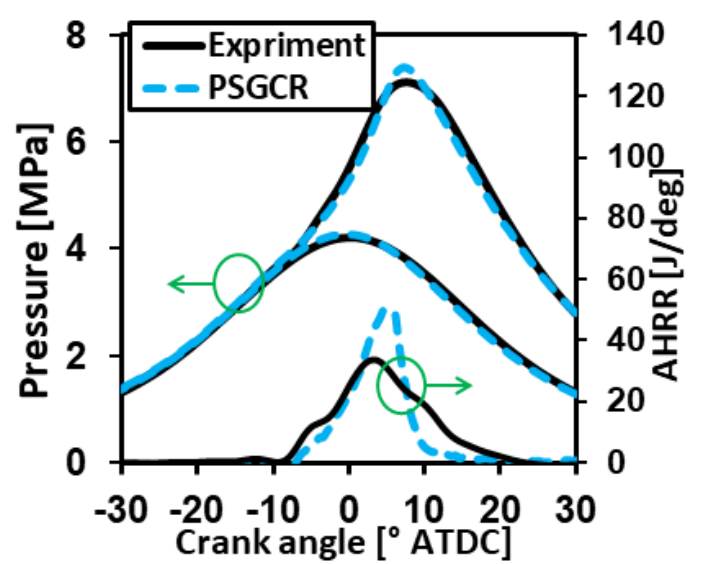

(a)

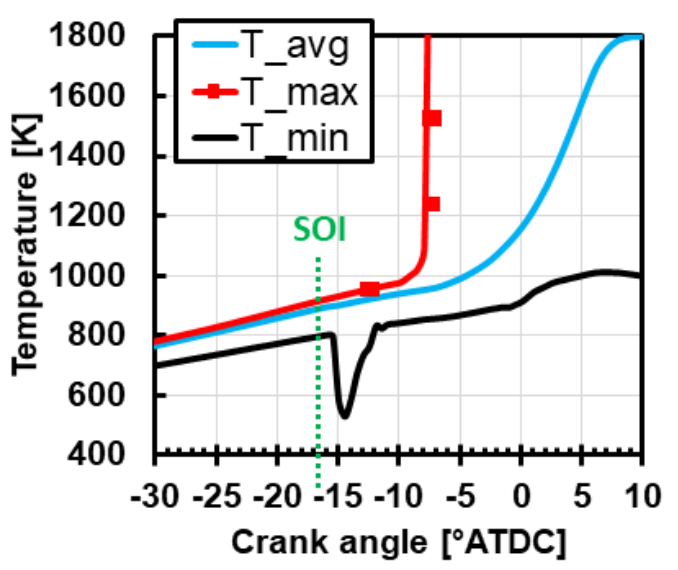

(b)

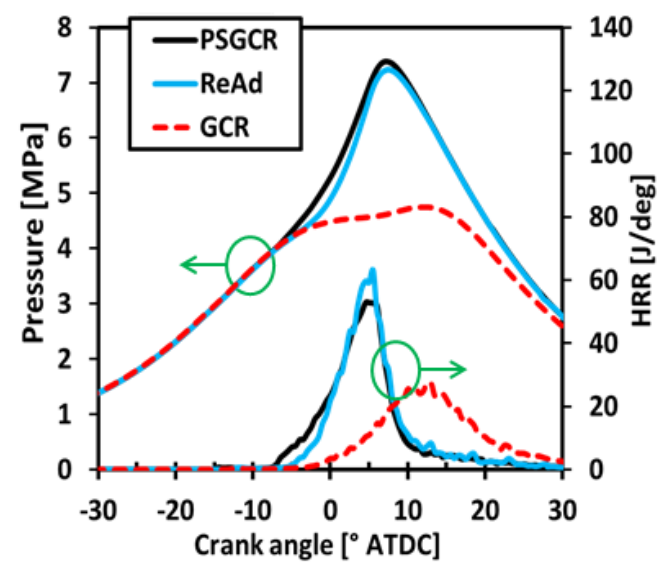

(c)

Figure 7-7: Comparison of (a) measured and predicted profiles of pressure and apparent heat release rate, (b) predicted maximum, minimum and average in-cylinder temperature based on the PSGCR model, (c) predicted pressure and heat release rate profiles based on different models

It is seen in Figure 7-7-(a) that noticeable heat release starts about $-8^{\circ}$ ATDC, which is after the end of the injection. It means that the high reactivity fuel- ULSD- mixes with the low reactivity fuel-methane- enough to form mixtures with optimal reactivity before the main ignition. Figure 7-7-(b) shows the profiles of the minimum, maximum, and mean in-cylinder gas temperatures. Due to diesel injection and subsequent vaporization, the local mixture temperatures drop after SOI, which is reflected in the minimum temperature profile. The sudden rise of the maximum local temperature profile around $8^{\circ} \mathrm{ATDC}$ indicates that ignition occurs. (The right prediction of local mixture reactivity in this temperature window is the key factor in the prediction of the ignition process and as the result pressure and heat release rate profile. Meanwhile, it is important to predict the right local mixing to be able to predict the local mixture reactivity. In current operating condition simulated here the local mixture with equivalence ratio of around 0.7 and 
temperature of around $950 \mathrm{~K}$ is the ignition-driving mixture). Note that, in the tested RCCI case, although the injection of diesel is very minimal $(1.64 \mathrm{mg})$ for a short time, the penetration of diesel fuel is long enough to form ignition-driving mixtures at the bottom of the bowl.

Simulation results by the three combustion models are compared in Figure 7-7-(c). A significant difference in predicted ignition timings is observed between the GCR model and the other two models. The ignition timing by the GCR model was substantially retarded, while the ReAd model shows a reasonable agreement with that of the PSGCR model. The reason for the retarded ignition timing of the GCR model is that all $n$-alkane components in the ULSD surrogate model are more reactive than n-heptane. In addition, iso-cetane (heptamethylnonane) and iso-decane (tetramethyl-hexane) show slightly higher reactivity than iso-octane at low to intermediate temperatures $(\mathrm{T}<1000 \mathrm{~K})$. Note that the $n$-alkanes are grouped and assigned to $n$-heptane and branched alkanes are grouped and assigned to iso-octane in both the GCR and ReAd model. Figure 7-8 shows the equivalence ratio and temperature distributions in the cylinder at $-5.5^{\circ} \mathrm{ATDC}$, which is right after the main ignition.

Since the same PS model is used, the non-reacting fuel distributions are expected to be almost identical for all three cases before the earliest ignition timing of the three cases. Even after ignition, the equivalence ratio of the mixture is uniform and equal to 0.5 over the entire cylinder before diesel injection. However, the fuel distributions start differing due to different combustion behavior. The temperature and equivalence ratio distributions predicted by the ReAd model are similar to those by the PSGCR model, which confirms that the reactivity and fuel consumption of local mixtures are well captured by the $\operatorname{Re} A d$ model.

The predicted ignition location (region at the bottom of the bowl enclosed by the $\mathrm{T}=1200 \mathrm{~K}$ contour) is similar between the ReAd model and the PSGCR model. However, the predicted area of high-temperature region is smaller in the ReAd model. The local high-temperature region ( $\mathrm{T}>1200 \mathrm{~K})$ is not seen in the case of GCR model, as shown in Figure 7-8-(a). 


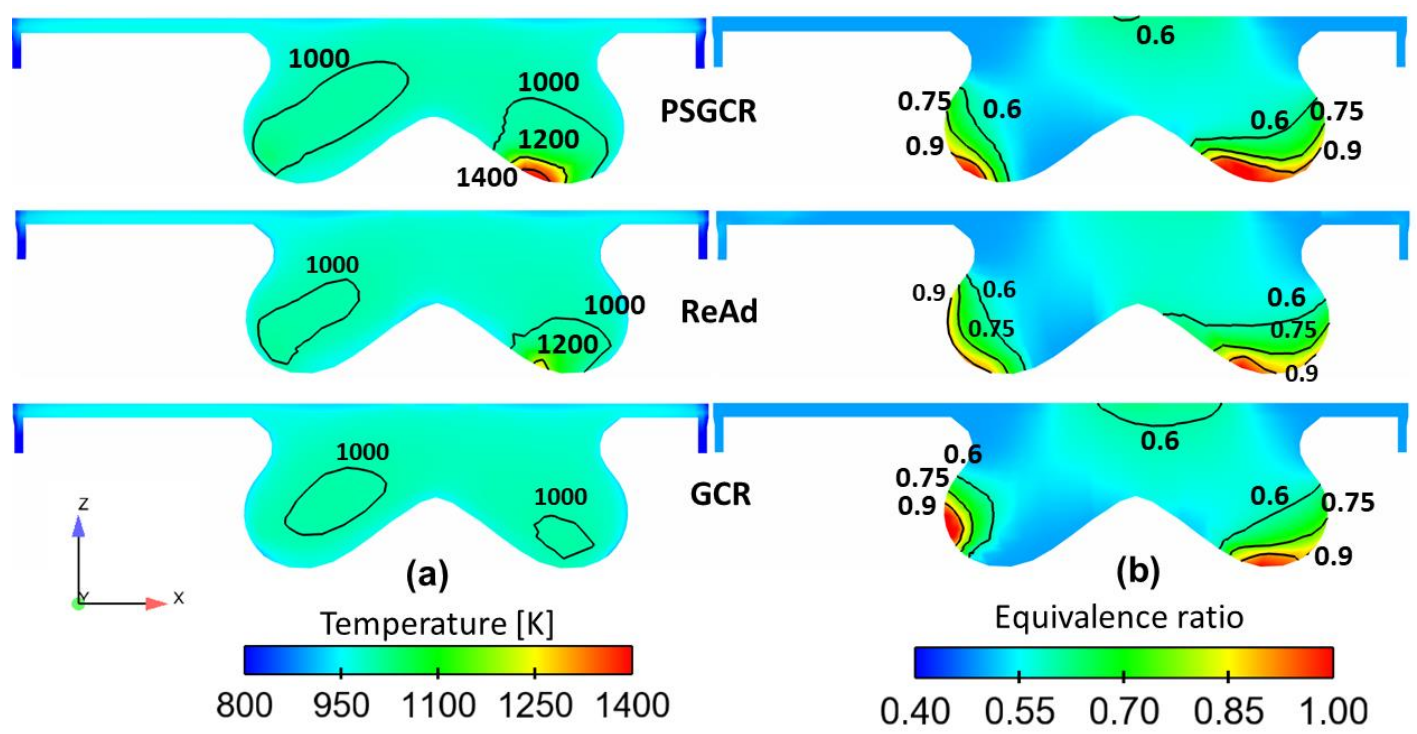

Figure 7-8: Comparison of predicted in-cylinder distribution of (a) temperature, (b) equivalence ratio in mid-plane view. Iso-contours of (a) temperature and (b) equivalence ratio are also plotted. The distributions are at $-5^{\circ} \mathrm{ATDC}$.

\subsection{Spray Combustion simulation in a Constant Volume Combustion Chamber}

When a multi-component spray is injected into a constant volume combustion chamber (CVCC), both thermal conditions and composition of local mixtures vary spatially and temporally. The ReAd model was applied to simulate spray combustion in a CVCC with FACE\#3 as the injected fuel.

The simulated operating conditions were set to those of the engine combustion network (ECN) Spray-A [67], except for the fuel model. The 12-component surrogate FACE\#3 suggested by Krishnasamy et al.[62] was used in the spray combustion simulations. The start of simulation is at the start of the injection and the simulation is terminated at the end of injection (5.5 ms after SOI). To reduce computation time, a 2-D grid that resolve $\frac{1}{360}$ degree of the chamber is used -similar to the CVCC case in Ref.[36] .

The PS composition of the FACE\#3 is listed in Table 7-5. Two different sets of CS models for GCR and ReAd models are tested. In the surrogate model with 3 components, n-heptane, iso-octane, and toluene are selected as the CS components and in another surrogate model n-heptane is selected as the single CS component. In both the GCR and the ReAd model, the assignment of PS components to the CS components are similar as shown in Table 7-5. Note that the PSGCR the PS components don't need to be grouped into chemical surrogate components because each PS component has its own CS component with reaction kinetics described in the mechanism. 
Table 7-5: 12-component FACE\#3 surrogate model

\begin{tabular}{|c|c|c|c|}
\hline \multirow{2}{*}{$\begin{array}{l}\text { 12-Component } \\
\text { FACE\#3 PS Model }\end{array}$} & \multirow[t]{2}{*}{$\begin{array}{l}\text { Mass } \\
\text { fraction }\end{array}$} & $\begin{array}{l}\text { ReAd \& GCR CS } \\
\text { model }\end{array}$ & $\begin{array}{l}\text { ReAd \& GCR } \\
\text { CS model }\end{array}$ \\
\hline & & $3 \mathrm{CS}$ components & $1 \mathrm{CS}$ component \\
\hline cetane, $\mathrm{C}_{16} \mathrm{H}_{34}(\mathrm{nA})$ & 0.080 & \multirow[b]{2}{*}{ n-heptane } & \multirow{12}{*}{ n-heptane } \\
\hline n-octadecane, $\mathrm{C}_{18} \mathrm{H}_{38}(\mathrm{nA})$ & 0.040 & & \\
\hline tetramethylhexane, $\mathrm{iC}_{10} \mathrm{H}_{22}(\mathrm{iA})$ & 0.095 & \multirow[b]{2}{*}{ iso-octane } & \\
\hline iso-cetane, $\mathrm{iC}_{16} \mathrm{H}_{34}(\mathrm{iA})$ & 0.100 & & \\
\hline cyclohexane, $\mathrm{C}_{6} \mathrm{H}_{12}(\mathrm{cA})$ & 0.050 & \multirow[b]{2}{*}{ n-heptane } & \\
\hline decalin, $\mathrm{C}_{10} \mathrm{H}_{18}(\mathrm{cA})$ & 0.200 & & \\
\hline m-xylene, $\mathrm{C}_{8} \mathrm{H}_{10}(\mathrm{mAH})$ & 0.020 & \multirow{4}{*}{ toluene } & \\
\hline tetralin, $\mathrm{C}_{10} \mathrm{H}_{12}(\mathrm{mAH})$ & 0.075 & & \\
\hline naphthalene, $\mathrm{C}_{10} \mathrm{H}_{8}(\mathrm{pAH})$ & 0.058 & & \\
\hline m-cymene, $\mathrm{C}_{10} \mathrm{H}_{14}(\mathrm{mAH})$ & 0.180 & & \\
\hline n-pentylbenzene, $\mathrm{C}_{11} \mathrm{H}_{16}(\mathrm{mAH})$ & 0.052 & \multirow{2}{*}{ n-heptane } & \\
\hline n-heptylbenzene, $\mathrm{C}_{13} \mathrm{H}_{20}(\mathrm{mAH})$ & 0.050 & & \\
\hline \multicolumn{4}{|c|}{ nA: normal-alkanes | iA: iso-Alkanes | cA: cyclo-alkanes | } \\
\hline
\end{tabular}

Figure 7-9-(a) shows a comparison of the profiles of the local maximum gas temperature in the combustion chamber predicted by the models. The IDTs correspond to the points at which the local temperature rises rapidly. It can be seen that the ignition timings of both CS models predicted by the ReAd model are in good agreement with that of the PSGCR method. On the contrary the GCR model predicts substantially early and retarded ignition with the 1 and 3 CS component models, respectively. The GCR model with the $1 \mathrm{CS}$ component represents the combustion kinetics of all components as $n$-heptane that has 
$\mathrm{CN}$ of $\sim 52$, which over-predicts the reactivity of FACE\#3 fuel $(\mathrm{CN}=27.9)$. However, the GCR model with the $3 \mathrm{CS}$ components under-predicts the reactivity of the target fuel since the mole-averaged $\mathrm{CN}$ of the 3-CS component model is lower $(\mathrm{CN}=27.0)$ than that of the target fuel. Note that the average CN of the CS composition does not reflect the performance of the ReAd model as is in the GCR model, since both the reactivity of local mixtures and the reactivity difference of individual PS components grouped into a CS component are taken into account by the model.

Figure 7-9-(b) shows the comparison of total computation times among the models. All simulations were performed using the same machine equipped with the Intel® Xeon X5650 processor. For the simulations with 3 CS components a reaction mechanism with 144 species and 594 reactions was employed while a reaction mechanism with 93 species and 345 reactions was used for the single CS simulations. Note that similar to the HCCI case, 3 CS reaction mechanism has 132 species and 1CS reaction mechanism has 81 species and 12 PS components of FACE\#3 are added as nominal species to both reaction mechanisms that are not involved in reactions (See Section.7.2 for more details).

As expected, the ReAd model with 3 CS components saves $37 \%$ of computation time compared to the PSGCR method that employs a larger mechanism (254 species and 1119 reactions). Note that this saving can be more significant when computation load increases as the number of computational-grid increases with more complex 3-D engine geometries. Interestingly, the simulation with the single CS ReAd models takes slightly less time compared to the simulation with the single CS GCR models. Detailed CPU time analysis of computational time illustrates that the CFD time-step gets smaller after the start of ignition, which makes the flow filed calculation costlier and as the result the total computation time of the simulation with the GCR model higher. The reason why the CFD time-step gets smaller is that pressure around the local igniting cell starts to increase rapidly after ignition as the result the CFD code decreases the time-step, $\Delta t$. (See Figure 7-10).

Although the single CS ReAd model can predict the ignition timings reasonably well, it is seen in Figure 7-9-(b) that the 3-CS ReAd model better captures the ignition timing of the PSGCR method. However, the ReAd model with single CS save around $20 \%$ of computation time compared the ReAd model with 3 CS components yet due to the limitation of single CS mentioned in Section.5. it is recommended to use the 3 CS component model at the expense of more computation time. 


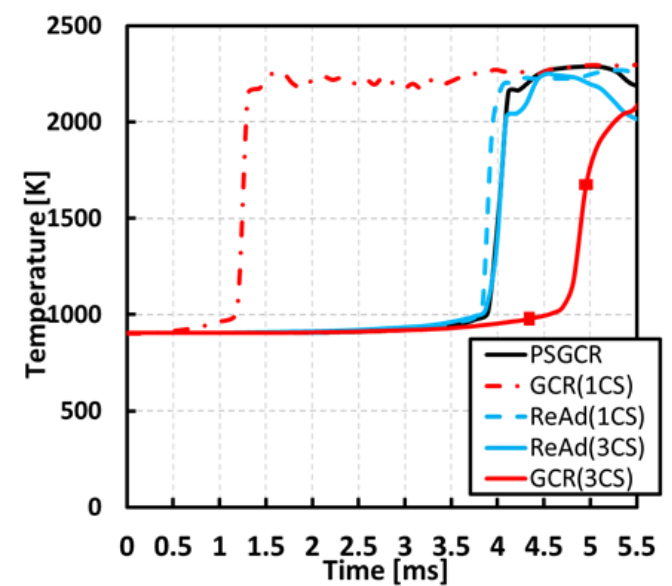

(a)

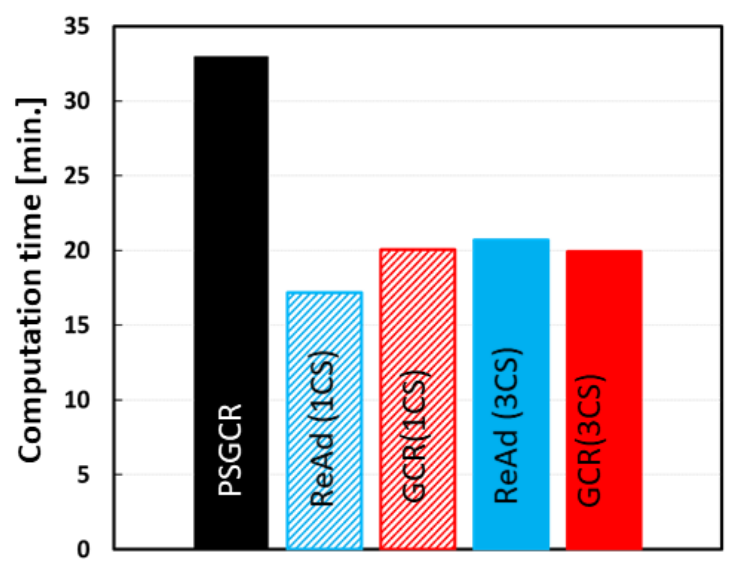

(b)

Figure 7-9: The predicted (a) maximum temperature based on different models in spray combustion simulation with FACE\#3, (b) total computation times for the spray combustion simulation with different combustion models

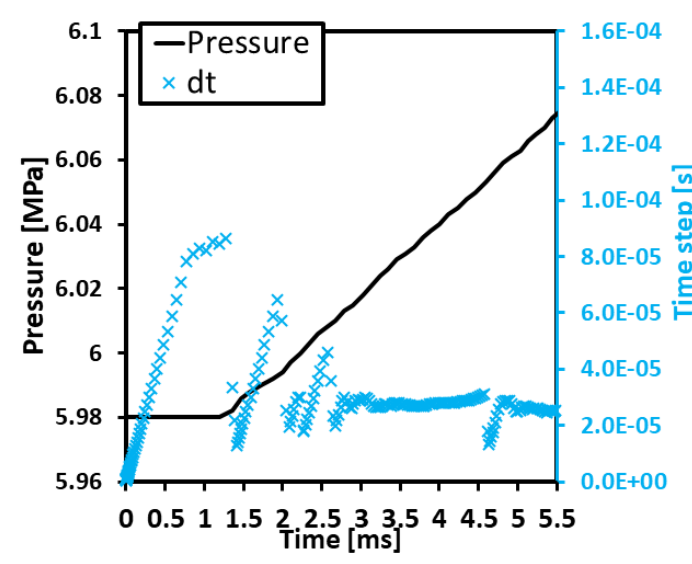

(a)

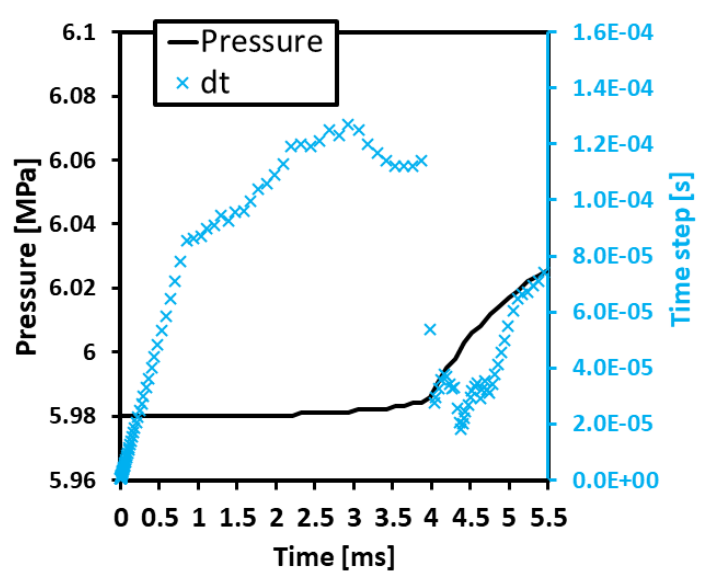

(b)

Figure 7-10: Comparison of pressure and CFD time-step for the CVCC spray combustion simulation between (a) GCR(1CS) model, (b) ReAd (1CS) model

Figure 7-12 till Figure 7-15 show the distributions of the unburned hydrocarbon (UHC) mass fraction and gas temperature from the start of ignition till the end of simulation for all of the CCCV spray cases. It can be seen that the location of ignition is influenced by the timing of ignition, and the temperature distributions predicted by both ReAd models look very similar to those by the PSGCR model. That is why the right prediction of ignition timing is so important in spray combustion simulations. 
The earlier ignition predicted by the 1CS GCR model is identified by the high temperature island at the ignition location near the tip of the spray (see Figure 7-11). On the contrary, the 3CS GCR model that predicts later ignition timing shows the ignition location near the bottom of the chamber ( see Figure 7-15). The total area of high temperature region $(\mathrm{T}>1300)$ at the end of the simulation $(\mathrm{T}=5.5 \mathrm{~ms})$ that can indicate the total heat release is also substantially different in the simulations that did not predict right ignition timing.

Additionally, since the same multi-component spray models were used in the all cases, it is expected that the UHC is almost identical before no significant reactions took place. It is shown that the UHC islands at the end of the simulation is similar among the 1CS ReAd, the 3CS ReAd and PSGCR models while those are completely different for the simulations with the 1CS GCR and the 3CS GCR models.
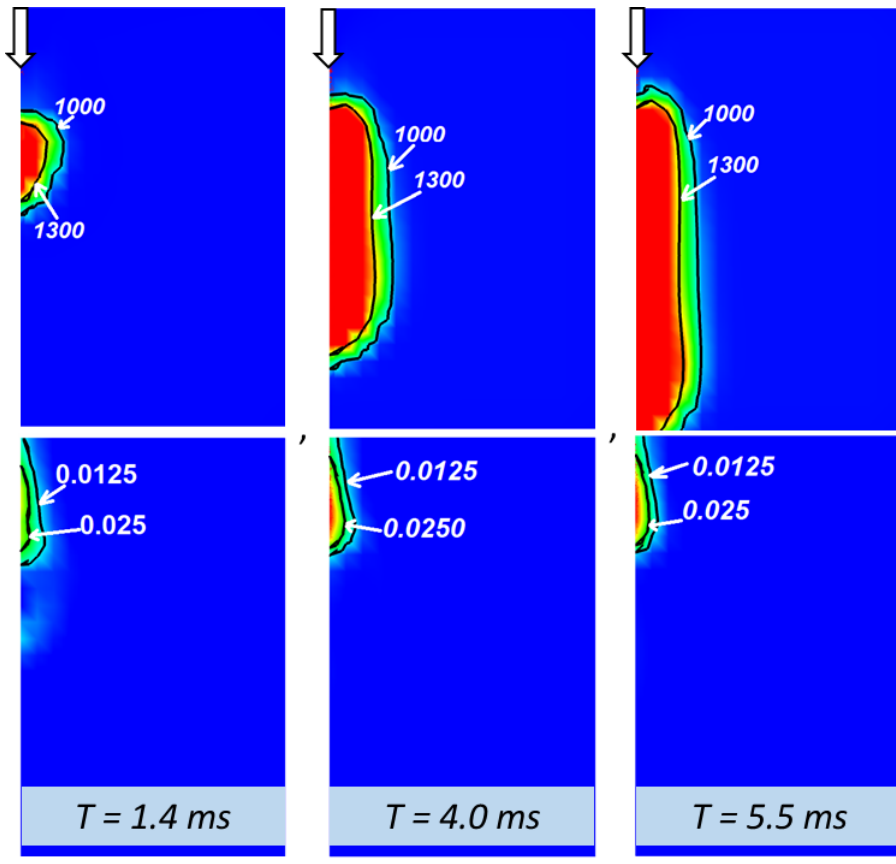

Temperature [K]

1300

1200

1100

1000

900

GCR 1CS

UHC

0.0500

0.0375

0.0250

0.0125

0.0000

Figure 7-11: Distribution of gas temperatures and unburned hydrocarbon mass fraction (UHC) in the CCCV simulation with 1CS GCR model 

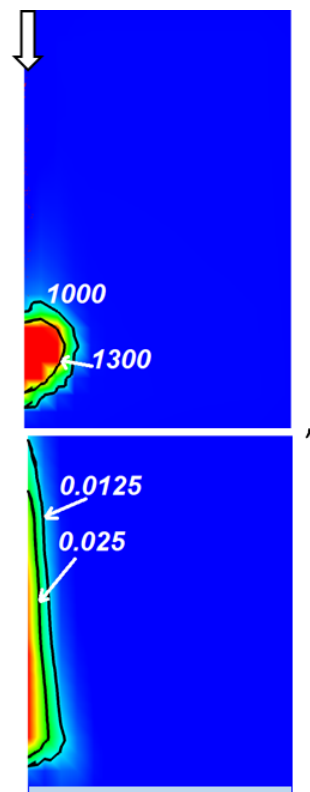

$T=4.0 \mathrm{~ms}$
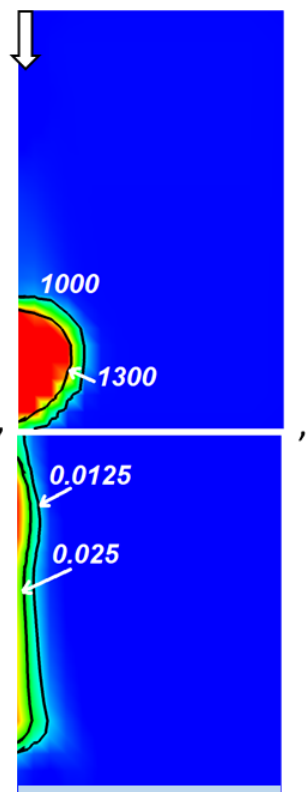

$T=4.5 \mathrm{~ms}$

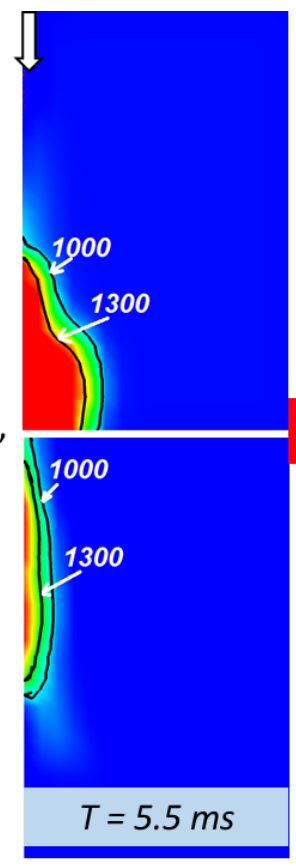

Temperature [K]

1300

1200

1100

1000

900

ReAd 1CS

UHC

0.0500

0.0375

0.0250

0.0125

0.0000

Figure 7-12: Distribution of gas temperatures and unburned hydrocarbon mass fraction (UHC) in the CCCV simulation with 1CS ReAd model
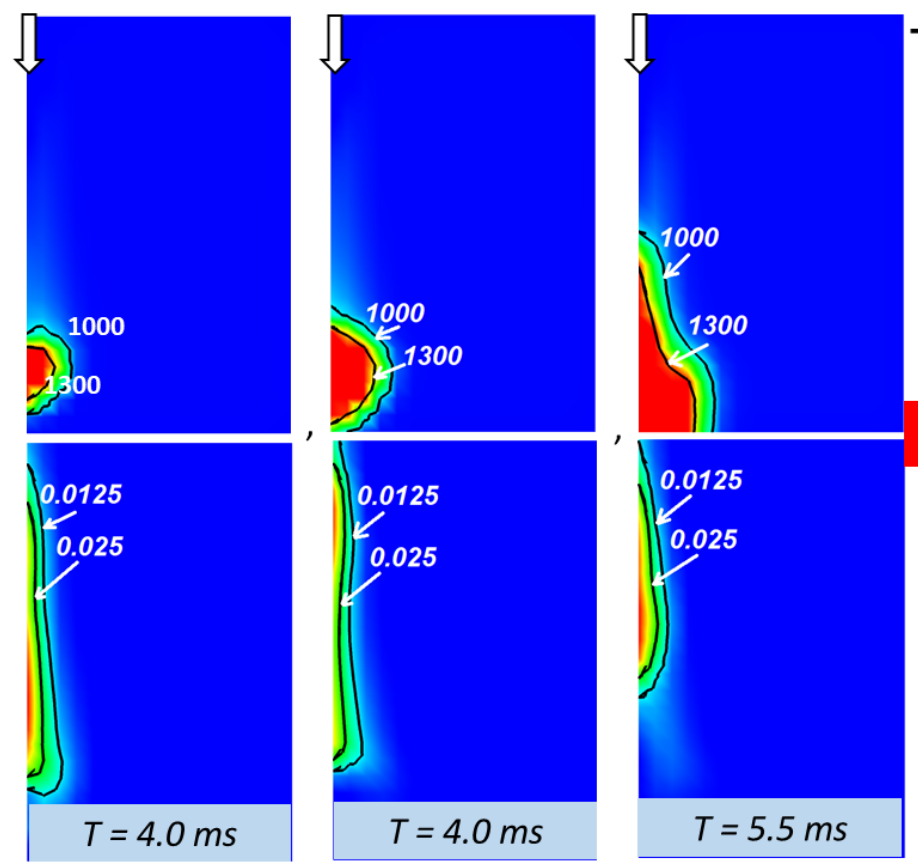

Temperature [K]

1300

1200

1100

1000

900

ReAd 3CS

UHC

0.0500

0.0375

0.0250

0.0125

0.0000

Figure 7-13: Distribution of gas temperatures and unburned hydrocarbon mass fraction (UHC) in the CCCV simulation with 1CS ReAd model 

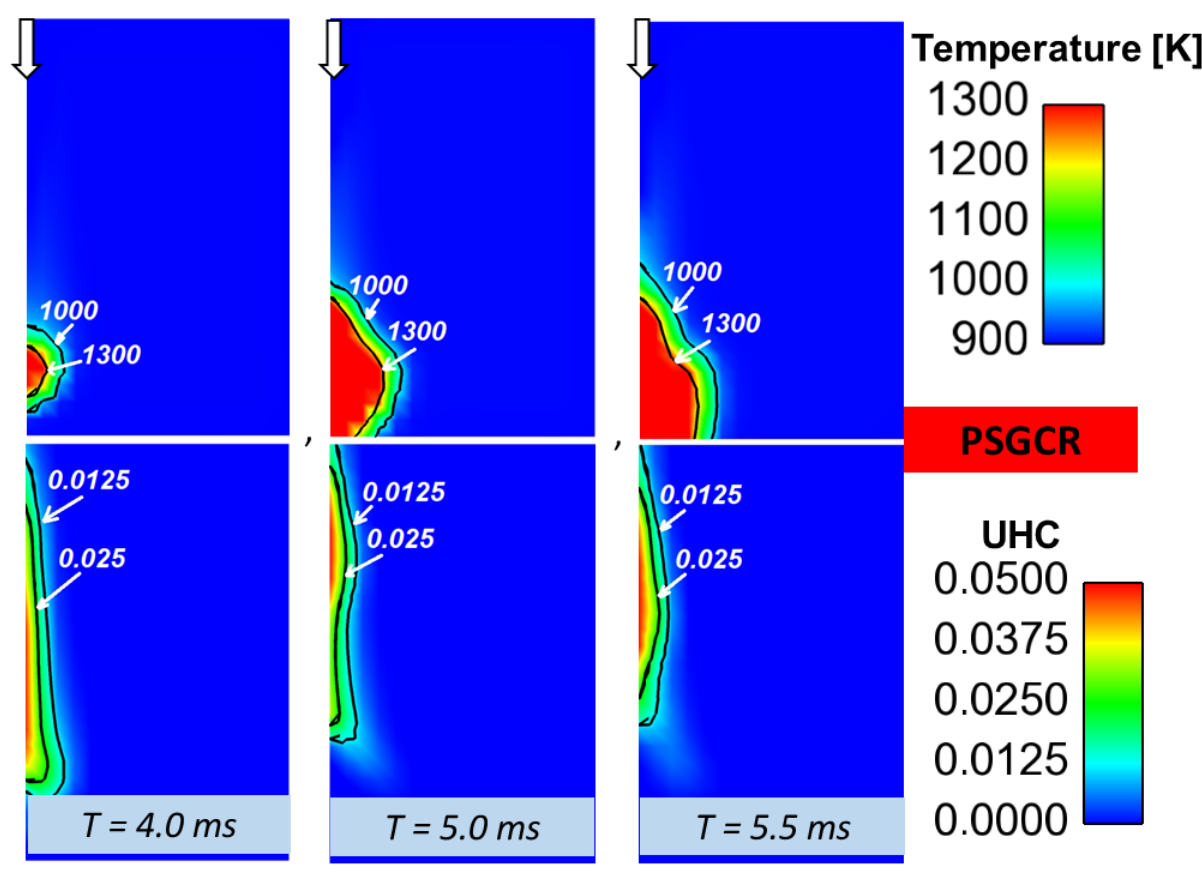

Figure 7-14: Distribution of gas temperatures and unburned hydrocarbon mass fraction (UHC) in the CCCV simulation with PSGCR model

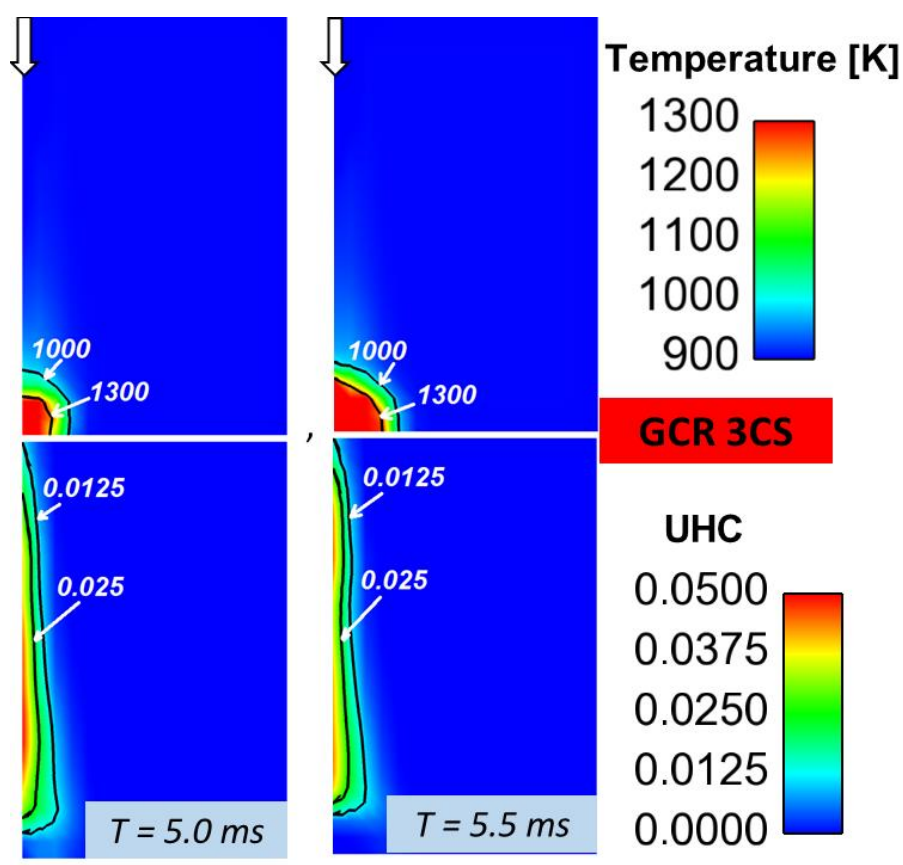

Figure 7-15: Distribution of gas temperatures and unburned hydrocarbon mass fraction (UHC) in the CCCV simulation with 3CS GCR model 


\section{Summary and Conclusions}

A combustion model to simulate the oxidation of multi-component fuels has been developed. The model is called reactivity adjustment $(\operatorname{Re} A d)$. The goal of the model is to represent the ignition characteristics of multiple physical surrogates with fewer chemical surrogates and achieve both computational efficiency and prediction accuracy. Starting with a single CS component (n-heptane) approach to represent the reactivity of n-alkanes fuels by adjusting the reaction rate constants of several characteristics reactions the CS component, the model was extended by adding two more chemical surrogate components to represent the ignition characteristics of fuel components in other chemical classes than n-alkanes. This enabled to avoid the excessive adjustment of reaction rate constants that is required when using a single chemical surrogate only.

The model was extensively tested for various fuels with a wide range of reactivity and in various combustion regimes including HCCI, RCCI and conventional diesel combustion. Compared to the group chemistry representation (GCR) approach, the present model demonstrates remarkable improvement of the ignition/combustion prediction for a 11 component FACE\#1 fuel in HCCI combustion, a 19-component ULSD in RCCI combustion, and a 12-component FACE\#3 in CVCC spray combustion. The performance of the present model also shows noticeable computation time benefit compared to the detailed chemistry calculation for the entire individual PS components. The HCCI simulations showed computation time saving by $79 \%$ and the CVCC spray simulations showed $37 \%$ saving. 


\section{Suggestions and Recommendations}

Further improvement of the presented combustion model can be addressed in future studies and some suggestions to pursue that goal are provided in this section.

The relative reactivity index (RRI) of a mixture that is defined in Eq. (4-2) is a linear function of the RRI of the components. In future studies, the non-linear behavior of fuel blending on mixture reactivity can be investigated.

The steps to make the $S_{f}$ correlation for a base-CS like Table 4-2 can be automated in future studies. Specifically, the selection of the control reactions, and the minimization of the error defined in Eq. (6-1) can be automated in future studies. Note that the significant part of the development time is spent in making high-fidelity correlations.

While it is desirable to achieve computational efficiency by reducing the number of CS at the minimum expense of prediction accuracy, addition of a base-CS from oxygenates chemical class is important in future studies if the existence of oxygenates components in the surrogate model is recommended. Grouping of oxygenates components to nonoxygenates hydrocarbons for chemical kinetic calculation can lead to remarkable error in the final results. 


\section{References}

[1] R. D. Reitz and G. Duraisamy, "Review of high efficiency and clean reactivity controlled compression ignition (RCCI) combustion in internal combustion engines," Progress in Energy and Combustion Science, vol. 46, pp. 12-71, 2015/02/01/ 2015, doi: https://doi.org/10.1016/j.pecs.2014.05.003.

[2] V. Manente, B. Johansson, and P. Tunestal, "Partially premixed combustion at high load using gasoline and ethanol, a comparison with diesel," SAE Technical Paper, 0148-7191, 2009.

[3] G. T. Kalghatgi, P. Risberg, and H.-E. Ångström, "Partially pre-mixed auto-ignition of gasoline to attain low smoke and low NOx at high load in a compression ignition engine and comparison with a diesel fuel," SAE Technical paper, 0148-7191, 2007.

[4] J. T. Farrell, R. Wagner, D. Gaspar, and C. Moen, Co-Optimization of Fuels \& Engines: FY18 Year in Review. ; National Renewable Energy Lab. (NREL), Golden, CO (United States), 2019, p. Medium: ED; Size: 3.8 MB.

[5] H. Wang et al., "A physics-based approach to modeling real-fuel combustion chemistry - I. Evidence from experiments, and thermodynamic, chemical kinetic and statistical considerations," Combustion and Flame, vol. 193, pp. 502-519, 2018/07/01/ 2018, doi: https://doi.org/10.1016/j.combustflame.2018.03.019.

[6] W. J. Pitz and C. J. Mueller, "Recent progress in the development of diesel surrogate fuels," Progress in Energy and Combustion Science, vol. 37, no. 3, pp. 330-350, 2011/06/01/ 2011, doi: https://doi.org/10.1016/j.pecs.2010.06.004.

[7] S. Singh, R. D. Reitz, and M. P. Musculus, "Comparison of the characteristic time (CTC), representative interactive flamelet (RIF), and direct integration with detailed chemistry combustion models against optical diagnostic data for multimode combustion in a heavy-duty DI diesel engine," SAE Technical Paper, 01487191, 2006.

[8] W. J. Pitz et al., "Development of an Experimental Database and Chemical Kinetic Models for Surrogate Gasoline Fuels," presented at the SAE, 2007. [Online]. Available: https://doi.org/10.4271/2007-01-0175.

[9] J. T. Farrell et al., "Development of an Experimental Database and Kinetic Models for Surrogate Diesel Fuels," 2007. [Online]. Available: https://doi.org/10.4271/2007-01-0201.

[10] K.-J. Myong, H. Suzuki, J. Senda, and H. Fujimoto, "Spray inner structure of evaporating multi-component fuel," Fuel, vol. 87, no. 2, pp. 202-210, 2008/02/01/ 2008, doi: https://doi.org/10.1016/j.fuel.2007.04.017. 
[11] J. L. Burger, M. E. Harries, and T. J. Bruno, "Characterization of Four Diesel Fuel Surrogates by the Advanced Distillation Curve Method," Energy \& Fuels, vol. 30, no. 4, pp. 2813-2820, 2016/04/21 2016, doi: 10.1021/acs.energyfuels.6b00107.

[12] Y. Ra and R. D. Reitz, "A vaporization model for discrete multi-component fuel sprays," International Journal of Multiphase Flow, vol. 35, no. 2, pp. 101-117, 2009/02/01/ 2009, doi: https://doi.org/10.1016/j.ijmultiphaseflow.2008.10.006.

[13] K. Mati, A. Ristori, S. Gaïl, G. Pengloan, and P. Dagaut, "The oxidation of a diesel fuel at 1-10atm: Experimental study in a JSR and detailed chemical kinetic modeling," Proceedings of the Combustion Institute, vol. 31, no. 2, pp. 2939-2946, 2007/01/01/ 2007, doi: https://doi.org/10.1016/j.proci.2006.07.073.

[14] B. M. Gauthier, D. F. Davidson, and R. K. Hanson, "Shock tube determination of ignition delay times in full-blend and surrogate fuel mixtures," Combustion and Flame, vol. 139, no. 4, pp. 300-311, 2004/12/01/ 2004, doi: https://doi.org/10.1016/j.combustflame.2004.08.015.

[15] J. C. G. Andrae, "Development of a detailed kinetic model for gasoline surrogate fuels," Fuel, vol. 87, no. 10, pp. 2013-2022, 2008/08/01/ 2008, doi: https://doi.org/10.1016/i.fuel.2007.09.010.

[16] O. Rajput, Y. Ra, and K.-P. Ha, "Numerical parametric study of a six-stroke gasoline compression ignition (GCI) engine combustion," SAE Technical Paper, 0148-7191, 2019.

[17] P. Dagaut and M. Cathonnet, "The ignition, oxidation, and combustion of kerosene: A review of experimental and kinetic modeling," Progress in Energy and Combustion Science, vol. 32, no. 1, pp. 48-92, 2006/01/01/ 2006, doi: https://doi.org/10.1016/j.pecs.2005.10.003.

[18] S. Honnet, K. Seshadri, U. Niemann, and N. Peters, "A surrogate fuel for kerosene," Proceedings of the Combustion Institute, vol. 32, no. 1, pp. 485-492, 2009/01/01/ 2009, doi: https://doi.org/10.1016/j.proci.2008.06.218.

[19] J. A. Cooke et al., "Computational and experimental study of JP-8, a surrogate, and its components in counterflow diffusion flames," Proceedings of the Combustion Institute, vol. 30, no. 1, pp. 439-446, 2005/01/01/ 2005, doi: https://doi.org/10.1016/j.proci.2004.08.046.

[20] K. Zhang et al., "An updated experimental and kinetic modeling study of n-heptane oxidation," Combustion and Flame, vol. 172, pp. 116-135, 2016/10/01/ 2016, doi: https://doi.org/10.1016/j.combustflame.2016.06.028. 
[21] T. Lu and C. K. Law, "A directed relation graph method for mechanism reduction," Proceedings of the Combustion Institute, vol. 30, no. 1, pp. 1333-1341, 2005/01/01/ 2005, doi: https://doi.org/10.1016/j.proci.2004.08.145.

[22] H. J. Curran, P. Gaffuri, W. J. Pitz, and C. K. Westbrook, "A Comprehensive Modeling Study of n-Heptane Oxidation," Combustion and Flame, vol. 114, no. 1, pp. 149-177, 1998/07/01/ 1998, doi: https://doi.org/10.1016/S00102180(97)00282-4.

[23] F. Perini, E. Galligani, and R. D. Reitz, "An Analytical Jacobian Approach to Sparse Reaction Kinetics for Computationally Efficient Combustion Modeling with Large Reaction Mechanisms," Energy \& Fuels, vol. 26, no. 8, pp. 4804-4822, 2012/08/16 2012, doi: 10.1021/ef300747n.

[24] K. Anand, Y. Ra, R. D. Reitz, and B. Bunting, "Surrogate Model Development for Fuels for Advanced Combustion Engines," Energy \& Fuels, vol. 25, no. 4, pp. 1474-1484, 2011/04/21 2011, doi: 10.1021/ef101719a.

[25] Y. Ra and R. D. Reitz, "A combustion model for IC engine combustion simulations with multi-component fuels," Combustion and Flame, vol. 158, no. 1, pp. 69-90, 2011/01/01/2011, doi: https://doi.org/10.1016/j.combustflame.2010.07.019.

[26] Y. Ra and R. D. Reitz, "A combustion model for multi-component fuels using a physical surrogate group chemistry representation (PSGCR)," Combustion and Flame, vol. 162, no. 10, pp. 3456-3481, 2015/10/01/ 2015, doi: https://doi.org/10.1016/j.combustflame.2015.05.014.

[27] Q. Jiao, Y. Ra, and R. D. Reitz, "Modeling the Influence of Molecular Interactions on the Vaporization of Multi-component Fuel Sprays," 2011. [Online]. Available: https://doi.org/10.4271/2011-01-0387.

[28] O. Rajput, Y. Ra, K.-P. Ha, and Y.-S. Son, "Numerical study on combustion characteristics of six-stroke-cycle gasoline compression ignition engine with continuously variable valve duration valve technology," International Journal of Engine Research, vol. 0, no. 0, p. 1468087419838390, 2019, doi: 10.1177/1468087419838390.

[29] A. A. Amsden, "KIVA-3V, release 2, improvements to KIVA-3V," Los Alamos National Laboratory, Los Alamos, NM, Report No. LA-UR-99-915, 1999.

[30] J. C. Beale and R. D. Reitz, "Modeling spray atomization with the KelvinHelmholtz/Rayleigh-Taylor hybrid model," Atomization and sprays, vol. 9, no. 6, 1999.

[31] A. B. Liu, D. Mather, and R. D. Reitz, "Modeling the effects of drop drag and breakup on fuel sprays," SAE Transactions, pp. 83-95, 1993. 
[32] Z. Han and R. D. Reitz, "Turbulence modeling of internal combustion engines using RNG $\kappa-\varepsilon$ models," Combustion science and technology, vol. 106, no. 4-6, pp. $267-$ 295, 1995.

[33] F. Perini, A. Krishnasamy, Y. Ra, and R. D. Reitz, "Computationally Efficient Simulation of Multicomponent Fuel Combustion Using a Sparse Analytical Jacobian Chemistry Solver and High-Dimensional Clustering," Journal of Engineering for Gas Turbines and Power, vol. 136, no. 9, p. 091515, 2014.

[34] Chemkin-Pro. (2008).

[35] M. A. Oehlschlaeger, J. Steinberg, C. K. Westbrook, and W. J. Pitz, "The autoignition of iso-cetane at high to moderate temperatures and elevated pressures: Shock tube experiments and kinetic modeling," Combustion and Flame, vol. 156, no. 11, pp. 2165-2172, 2009/11/01/ 2009, doi: https://doi.org/10.1016/j.combustflame.2009.05.007.

[36] A. Jamali, Y. Ra, W. Park, and G. Cho, "A Combustion Model for MultiComponent Fuels Based on Reactivity Concept and Single-Surrogate Chemistry Representation," 2018. [Online]. Available: https://doi.org/10.4271/2018-01-0260.

[37] J. Yanowitz, M. A. Ratcliff, R. L. McCormick, J. D. Taylor, and M. J. Murphy, "Compendium of experimental cetane numbers," National Renewable Energy Lab.(NREL), Golden, CO (United States), 2017.

[38] H. K. Ciezki and G. Adomeit, "Shock-tube investigation of self-ignition of nheptane-air mixtures under engine relevant conditions," Combustion and Flame, vol. 93, no. 4, pp. 421-433, 1993/06/01/ 1993, doi: https://doi.org/10.1016/00102180(93)90142-P.

[39] J. Huang and W. K. Bushe, "Experimental and kinetic study of autoignition in methane/ethane/air and methane/propane/air mixtures under engine-relevant conditions," Combustion and Flame, vol. 144, no. 1, pp. 74-88, 2006/01/01/ 2006, doi: https://doi.org/10.1016/j.combustflame.2005.06.013.

[40] K. Fieweger, R. Blumenthal, and G. Adomeit, "Self-ignition of S.I. engine model fuels: A shock tube investigation at high pressure," Combustion and Flame, vol. 109, no. 4, pp. 599-619, 1997/06/01/ 1997, doi: https://doi.org/10.1016/S00102180(97)00049-7.

[41] Y. Ra, F. Chuahy, and S. Kokjohn, "Development and validation of a reduced reaction mechanism with a focus on diesel fuel/syngas co-oxidation," Fuel, vol. 185, pp. 663-683, 12/1/ 2016, doi: https://doi.org/10.1016/j.fuel.2016.07.039.

[42] M. Mehl, W. J. Pitz, C. K. Westbrook, and H. J. Curran, "Kinetic modeling of gasoline surrogate components and mixtures under engine conditions," 
Proceedings of the Combustion Institute, vol. 33, no. 1, pp. 193-200, 2011/01/01/ 2011, doi: https://doi.org/10.1016/j.proci.2010.05.027.

[43] S. M. Sarathy et al., "Comprehensive chemical kinetic modeling of the oxidation of 2-methylalkanes from C7 to C20," Combustion and Flame, vol. 158, no. 12, pp. 2338-2357, 2011/12/01/ 2011, doi: https://doi.org/10.1016/j.combustflame.2011.05.007.

[44] D. Healy et al., "n-Butane: Ignition delay measurements at high pressure and detailed chemical kinetic simulations," Combustion and Flame, vol. 157, no. 8, pp. 1526-1539, 2010/08/01/ 2010, doi: https://doi.org/10.1016/j.combustflame.2010.01.016.

[45] S. M. Sarathy, A. Farooq, and G. T. Kalghatgi, "Recent progress in gasoline surrogate fuels," Progress in Energy and Combustion Science, vol. 65, pp. 67-108, 2018/03/01/ 2018, doi: https://doi.org/10.1016/j.pecs.2017.09.004.

[46] C. Morley, "A Fundamentally Based Correlation Between Alkane Structure and Octane Number," Combustion Science and Technology, vol. 55, no. 4-6, pp. 115123, 1987/10/01 1987, doi: 10.1080/00102208708947074.

[47] W. Wang et al., "An experimental and modeling study of the autoignition of 3methylheptane," Proceedings of the Combustion Institute, vol. 34, no. 1, pp. 335343, 2013/01/01/ 2013, doi: https://doi.org/10.1016/j.proci.2012.06.001.

[48] Y. Li, C.-W. Zhou, K. P. Somers, K. Zhang, and H. J. Curran, "The oxidation of 2butene: A high pressure ignition delay, kinetic modeling study and reactivity comparison with isobutene and 1-butene," Proceedings of the Combustion Institute, vol. 36, no. 1, pp. 403-411, 2017/01/01/ 2017, doi: https://doi.org/10.1016/j.proci.2016.05.052.

[49] J. Bugler et al., "An experimental and modelling study of n-pentane oxidation in two jet-stirred reactors: The importance of pressure-dependent kinetics and new reaction pathways," Proceedings of the Combustion Institute, vol. 36, no. 1, pp. 441-448, 2017/01/01/2017, doi: https://doi.org/10.1016/j.proci.2016.05.048.

[50] S. Y. Mohamed et al., "Modeling Ignition of a Heptane Isomer: Improved Thermodynamics, Reaction Pathways, Kinetics, and Rate Rule Optimizations for 2-Methylhexane," The Journal of Physical Chemistry A, vol. 120, no. 14, pp. 2201 2217, 2016/04/14 2016, doi: 10.1021/acs.jpca.6b00907.

[51] S. M. Sarathy et al., "A comprehensive combustion chemistry study of 2,5dimethylhexane," Combustion and Flame, vol. 161, no. 6, pp. 1444-1459, 2014/06/01/ 2014, doi: https://doi.org/10.1016/j.combustflame.2013.12.010. 
[52] J. Bugler et al., "An ignition delay time and chemical kinetic modeling study of the pentane isomers," Combustion and Flame, vol. 163, pp. 138-156, 2016/01/01/ 2016, doi: https://doi.org/10.1016/j.combustflame.2015.09.014.

[53] K. Zhang et al., "An experimental and kinetic modeling study of the oxidation of hexane isomers: Developing consistent reaction rate rules for alkanes," Combustion and Flame, vol. 206, pp. 123-137, 2019/08/01/ 2019, doi: https://doi.org/10.1016/j.combustflame.2019.04.011.

[54] Y. Zhang, K. P. Somers, M. Mehl, W. J. Pitz, R. F. Cracknell, and H. J. Curran, "Probing the antagonistic effect of toluene as a component in surrogate fuel models at low temperatures and high pressures. A case study of toluene/dimethyl ether mixtures," Proceedings of the Combustion Institute, vol. 36, no. 1, pp. 413-421, 2017/01/01/ 2017, doi: https://doi.org/10.1016/j.proci.2016.06.190.

[55] R. Bounaceur, I. Da Costa, R. Fournet, F. Billaud, and F. Battin-Leclerc, "Experimental and modeling study of the oxidation of toluene," International journal of chemical kinetics, vol. 37, no. 1, pp. 25-49, 2005.

[56] W. K. Metcalfe, S. Dooley, and F. L. Dryer, "Comprehensive Detailed Chemical Kinetic Modeling Study of Toluene Oxidation," Energy \& Fuels, vol. 25, no. 11, pp. 4915-4936, 2011/11/17 2011, doi: 10.1021/ef200900q.

[57] J. C. G. Andrae, P. Björnbom, R. F. Cracknell, and G. T. Kalghatgi, "Autoignition of toluene reference fuels at high pressures modeled with detailed chemical kinetics," Combustion and Flame, vol. 149, no. 1, pp. 2-24, 2007/04/01/ 2007, doi: https://doi.org/10.1016/j.combustflame.2006.12.014.

[58] D. Darcy et al., "A high pressure shock tube study of n-propylbenzene oxidation and its comparison with n-butylbenzene," Combustion and Flame, vol. 159, no. 7, pp. 2219-2232, 2012/07/01/ 2012, doi: https://doi.org/10.1016/j.combustflame.2012.02.009.

[59] A. Roubaud, R. Minetti, and L. R. Sochet, "Oxidation and combustion of low alkylbenzenes at high pressure: comparative reactivity and auto-ignition," Combustion and Flame, vol. 121, no. 3, pp. 535-541, 2000/03/01/ 2000, doi: https://doi.org/10.1016/S0010-2180(99)00169-8.

[60] J. A. Snyman and D. N. Wilke, Practical Mathematical Optimization: Basic Optimization Theory and Gradient-Based Algorithms. Springer International Publishing, 2018.

[61] B. G. Bunting, S. J. Eaton, and R. W. Crawford, "Performance Evaluation and Optimization of Diesel Fuel Properties and Chemistry in an HCCI Engine," 2009. [Online]. Available: https://doi.org/10.4271/2009-01-2645. 
[62] A. Krishnasamy, Y. Ra, R. D. Reitz, and B. Bunting, "Combustion simulations of the fuels for advanced combustion engines in a homogeneous charge compression ignition engine," International Journal of Engine Research, vol. 14, no. 2, pp. 191208, 2013, doi: 10.1177/1468087412454066.

[63] C. Wilhelmsson, A. Vressner, P. Tunestål, B. Johansson, G. Särner, and M. Aldén, "Combustion Chamber Wall Temperature Measurement and Modeling During Transient HCCI Operation," 2005. [Online]. Available: https://doi.org/10.4271/2005-01-3731.

[64] E. Ansari, K. Poorghasemi, B. Khoshbakht Irdmousa, M. Shahbakhti, and J. Naber, "Efficiency and Emissions Mapping of a Light Duty Diesel - Natural Gas Engine Operating in Conventional Diesel and RCCI Modes," presented at the SAE, 2016. [Online]. Available: https://doi.org/10.4271/2016-01-2309.

[65] I. C. ANSYS, "Release 10.0: Tutorial Manual," ed: ANSYS, Inc., Canonsburg, 2005.

[66] J. Huang, P. G. Hill, W. K. Bushe, and S. R. Munshi, "Shock-tube study of methane ignition under engine-relevant conditions: experiments and modeling," Combustion and Flame, vol. 136, no. 1, pp. 25-42, 2004/01/01/ 2004, doi: https://doi.org/10.1016/j.combustflame.2003.09.002.

[67] G. B. L. Pickett, R. Payri. Engine Combust. Network [Online] Available: https://ecn.sandia.gov/ 